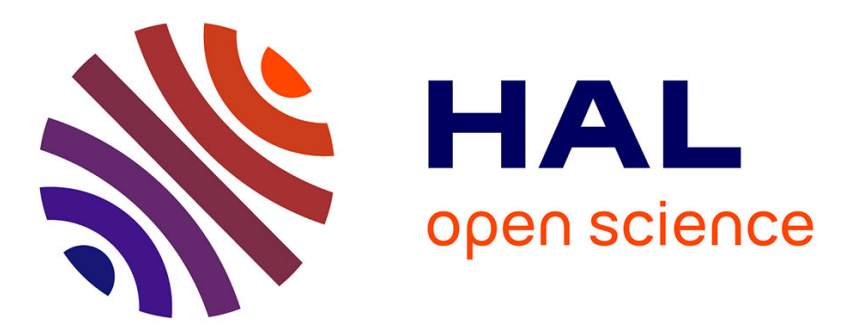

\title{
Dynamic Thermal Behaviour Characterization Of Integrated Insulation Clay Hollow Blocks For Buildings Energy Simulations Applications
}

\author{
Jean-Baptiste Bouvenot, Vincent Jimenez, Lucas Desport
}

\section{To cite this version:}

Jean-Baptiste Bouvenot, Vincent Jimenez, Lucas Desport. Dynamic Thermal Behaviour Characterization Of Integrated Insulation Clay Hollow Blocks For Buildings Energy Simulations Applications. Journal of Building Engineering, 2021, 10.1080/19401493.2021.1975824 . hal-03402840

\author{
HAL Id: hal-03402840 \\ https://hal.science/hal-03402840
}

Submitted on 25 Oct 2021

HAL is a multi-disciplinary open access archive for the deposit and dissemination of scientific research documents, whether they are published or not. The documents may come from teaching and research institutions in France or abroad, or from public or private research centers.
L'archive ouverte pluridisciplinaire HAL, est destinée au dépôt et à la diffusion de documents scientifiques de niveau recherche, publiés ou non, émanant des établissements d'enseignement et de recherche français ou étrangers, des laboratoires publics ou privés. 


\title{
Dynamic Thermal Behavior Characterization Of Integrated Insulation Clay Hollow Blocks For Buildings Energy Simulations Applications
}

\author{
Jean-Baptiste Bouvenot ${ }^{1,2^{*}}$, Vincent Jimenez ${ }^{1}$, Lucas Desport ${ }^{1}$ \\ ${ }^{1}$ National Institute of Applied Sciences of Strasbourg, Strasbourg, France \\ ${ }^{2}$ ICube Laboratory, Strasbourg, France
}

${ }^{I}$ INSA de Strasbourg, 24 boulevard de la victoire, 67084 Strasbourg Cedex, France

${ }^{2}$ ICube UMR 7357 - Laboratoire des sciences de l'ingénieur, de l'informatique et de l'imagerie, 300 bd Sébastien Brant - CS 10413 F-67412 Illkirch Cedex

Main author:

Jean-Baptiste BOUVENOT (jean-baptiste.bouvenot@insa-strasbourg.fr)

Tel: +33(0)388144967

http://orcid.org/0000-0002-9193-1569

Keywords: clay hollow block; integrated insulation clay hollow block; dynamic thermal behaviour; in situ tests; guarded hot box; TRNSYS simulations 


\begin{abstract}
A method is proposed to obtain the thermal properties of hollow clay blocks with integrated insulation for use in building energy simulation tools. Then, we show the significant impact of the interior coating on the dynamic thermal behaviour of these blocks. This method is composed of two numerical and two experimental phases. First, a numerical model in unsteady regime has been created and calibrated by experimental studies on a wall sample tested in a guarded hot box. Finally, a validation phase is carried out by comparing TRNSYS simulations with in situ test data from a residential building. Finally, we provide reliable values for the thermal properties to be used in energy simulation software (equivalent thermal conductivity of $0.08 \mathrm{~W} \cdot \mathrm{m}^{-1} \cdot \mathrm{K}^{-1}$, equivalent density of $630 \mathrm{~kg} \cdot \mathrm{m}^{-3}$ and equivalent heat capacity of $430 \mathrm{~J} \cdot \mathrm{kg}^{-}$ $\left.{ }^{1} \cdot \mathrm{K}^{-1}\right)$.
\end{abstract}

\title{
1. Introduction
}

Most building materials are homogeneous and their physical properties (thermal conductivity $\lambda$, density $\rho$, heat capacity $c_{p}$ ) are often well known and compiled in reliable databases [1] or in buildings energy simulation tools such as TRNSYS, Energy Plus, Design Builder, or Pleiades COMFIE for example. However, this approach is not well suited to many building materials due to their geometry complexity, such as hollow blocks. Integrated insulation clay hollow blocks are an interesting building system in the context of Near Zero Energy Buildings (NZEB) and energy efficiency because they offer higher thermal insulation for the same thickness compared to clay hollow blocks by filling the cavities with mineral wool. In addition, unlike conventional clay hollow blocks, integrated insulation clay hollow blocks do not require an additional layer (inside or outside) of thermal insulation to achieve the building performance standards. Furthermore, the objective of summer comfort is becoming a major concern in the European context, especially with regard to future climate change [2]. The dynamic thermal behavior of this type of blocks needs to be well known in order to assess its natural performance to guarantee this summer comfort in a passive way Therefore, it is important to know the classical thermal properties (thermal conductivity, density and heat capacity) of these complex blocks in order to perform reliable energy building simulations. Integrated insulation clay hollow blocks have a complex geometry with 2 different materials: clay and mineral wool along high thickness (from 30 to $42.5 \mathrm{~cm}$ here) (see Figure 1) with integrated thermal bridges. The equivalent thermal conductivity $\lambda_{e q}$ (or thermal resistance $R$ in $\mathrm{m}^{2} . \mathrm{K} \mathrm{W}^{-1}$ ) is often well known [3-13] or well compiled [1] for energetic calculations. However, the equivalent density $\rho_{e q}$ and mainly heat capacity $c_{p e q}$ are poorly assessed or are assessed by simplified methods [14-18] although some authors note the difficulty of modelling 2D or 3D blocks in 1D because of their complex design [7]. Many authors only work on hollow clay blocks but the majority of them investigates only the steady state behaviour $\left(\lambda_{e q}\right)$ [3-13]. Some authors have worked on their dynamic thermal behaviour [14, 16, 19-24] without quantifying the equivalent density and heat capacity but by investigating others transient indicators (time-lag, phase shifting, block response time, heat-flux decrement factor). Some authors also propose complex methods for modelling complex walls or thermal bridges using multi layers materials [23, 24] but require complex calculation of structure factors. More generally, several works dealt with the thermal comfort of clay bricks [19, 25] but most of them study heavy clay blocks with sometimes ill-adapted experimental set up (indoor temperature imposed to constant value to study temperature damping performances [19]). In addition, there are different ways of constructing walls made of such bricks (plaster coating or plasterboard with air layer, amount of glue) which can change the dynamic thermal properties of the whole wall [5,6]. For more modern bricks integrating mineral insulation in bigger cavities (see Fig. 1), the question of the dynamic thermal behaviour will be more crucial because if the insulation is integrated and therefore distributed, the thermal mass is also distributed. The problem is that despite the mass of clay, what is the effective thermal inertia provided by this type of block for the natural control of the ambient temperature? Furthermore, what is the influence of the construction 
method (plaster board or plaster coating) on the dynamic thermal behaviour? Most of the authors perform either only numerical approaches [3-6, 8-10, 12-16, 21-23], or both numerical and experimental approaches with hotboxes $[7,11,17,18,20,24]$ or both numerical and experimental with in situ tests approaches [2326], but none of them proposes a complete procedure combining all these approaches for integrated insulation clay hollow blocks. Some authors study only one block in small hotboxes $[18,20]$ without taking into account inner and outer coating, mortar or glue impacts but but the majority of studies consider larger wall samples to take into account blocks group effects, mortar effects and to avoid edge effects. Some authors also study this type of blocks without considering cyclic thermal edge conditions [18]. The novelty of this work is to propose an original and complete approach on the dynamic thermal properties characterization of integrated insulation clay hollow blocks by a complete procedure from a 1D numerical model, a 2D numerical model, experimental tests on a $1 \mathrm{~m}^{2}$ wall sample, in situ tests and TRNSYS simulations.

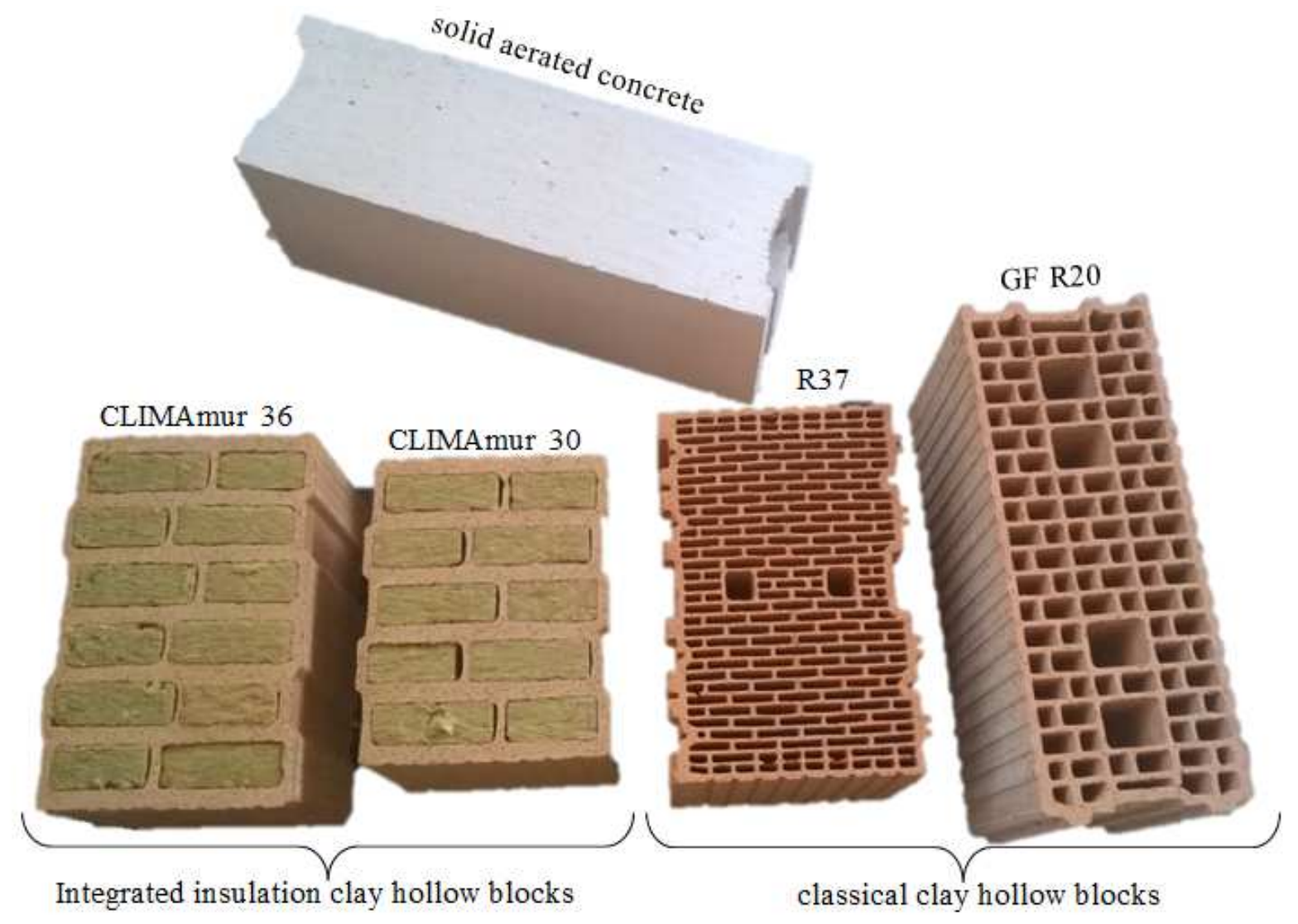

Figure 1: Tested brick types: Integrated insulation clay hollow blocks (left), classical hollow clay blocks (right) and solid aerated concrete blocks (top) samples (Wienerberger clay hollow bricks references from left to right: CLIMAmur 36, CLIMAmur 30, R37, GF R20).

The objective here is to propose a method to obtain the equivalent parameters linked to the dynamic thermal behaviour to be used in an energy building simulation tool, which generally assumes uniform materials layers and 1D heat transfers. Then, the aim is to evaluate the impact of the construction mode (plasterboard or plaster coating on the inner face) of this type of wall on the dynamic thermal properties. This method is composed of a numerical phase and an experimental phase. At first, a 1D finite difference model was created to simulate the thermal behaviour of this type of block. Then, an experimental test bench has been created. It consists of two $1 \mathrm{~m}^{3}$ climatic chambers and a $1 \mathrm{~m}^{2}$ wall-mounted sample holder (guarded hotbox). Each chamber dynamically simulates indoor and outdoor climates (temperature and relative humidity) and the blocks are equipped by heat flux sensors and type-K thermocouples along the thickness. The objective is to calibrate the 1D model on the basis on experimental data. An optimisation procedure is used to identify the equivalent thermal properties of a uniform block, which has the same dynamic thermal behavior. Finally, a validation is carried out by comparing TRNSYS simulations and in situ test data in a residential building. In 
addition, two tests were carried out in the climatic chambers to compare the two construction methods (plasterboard with air layer generated by sealing glue points and plaster coating without air layer). This last study is important because in most cases, these blocks are covered by plasterboards generating an air layer that increases the thermal insulation but that can "cut off" access to thermal inertia.

\section{Method}

The method is composed of 2 phases. Each phase is composed of an experimental part and a numerical part. In the first phase, an experimental study is carried out to investigate the steady and unsteady states thermal behaviour of a wall sample $\left(1 \mathrm{~m}^{2}\right)$ under controlled conditions with a guarded hot box composed of two $1 \mathrm{~m}^{3}$ climatic chambers and a $1 \mathrm{~m}^{2}$ wall sample holder (guarded hot box). Each chamber dynamically simulates the indoor and outdoor climates (temperature and humidity). Two procedures will be distinguished to determine the equivalent thermal conductivity by using steady state tests on the one hand and unsteady state tests to identify the dynamic thermal properties $\left(\rho_{e q}\right.$ and $\left.c_{p e q}\right)$ on the other hand. In parallel, a 1D finite difference model is programmed to simulate the dynamic thermal behaviour of these blocks. An optimisation procedure based on the classical least squares method will compare the 1D model outputs with the experimental outputs to find the equivalent thermal properties: $\left(\rho_{e q}\right.$ and $\left.c_{p e q}\right), \lambda_{e q}$, being determined by steady state tests. Then, for the second phase, we will use the equivalent thermal properties in a TRNSYS simulation modelling a real residential building. In parallel, we perform an in situ test in this real building using a specific and dedicated weather station (the measured weather data will be used in the TRNSYS simulation), and non-intrusive/non-destructive metrology on the surface of walls in particular, (temperature probes, heat flux sensors and shading position sensors). Finally, we validate the equivalent properties by comparing TRNSYS outputs with in situ tests measurements. Figure 2 summarises our scientific approach:



Figure 2: Flow chart of the method.

\subsection{Experimental test bench}

The first step of the method is to carry out experimental tests on a $1 \mathrm{~m}^{2}$ wall sample built between two $1 \mathrm{~m}^{3}$ climatic chambers whose ambiances are dynamically controlled. The first climatic room emulates indoor conditions; the second emulates outdoor conditions (see. Fig. 3). 


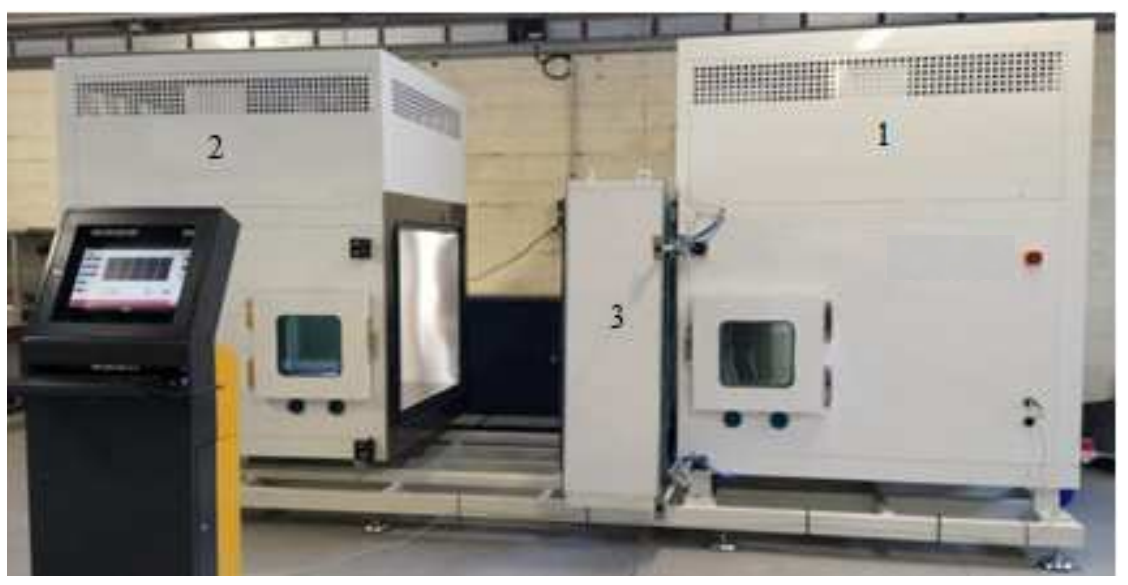

Figure 3: Test bench (1: indoor climatic room, 2: outdoor climatic room, 3: wall sample holder).

Some authors propose to study the dynamic thermal behaviour of the block using constant air temperatures or air temperature differences between inside and outside [18, 19, 26], but the results cannot be representative of more realistic periodic thermal loads. The winter and summer outdoor climates were emulated by the hot box by using 2 sine curves over $24 \mathrm{~h}$. The parameters of the curves (min, max and damping) are based on an average French climate for winter and summer seasons, avoiding extreme conditions (cold or heat waves), (see Fig 4).

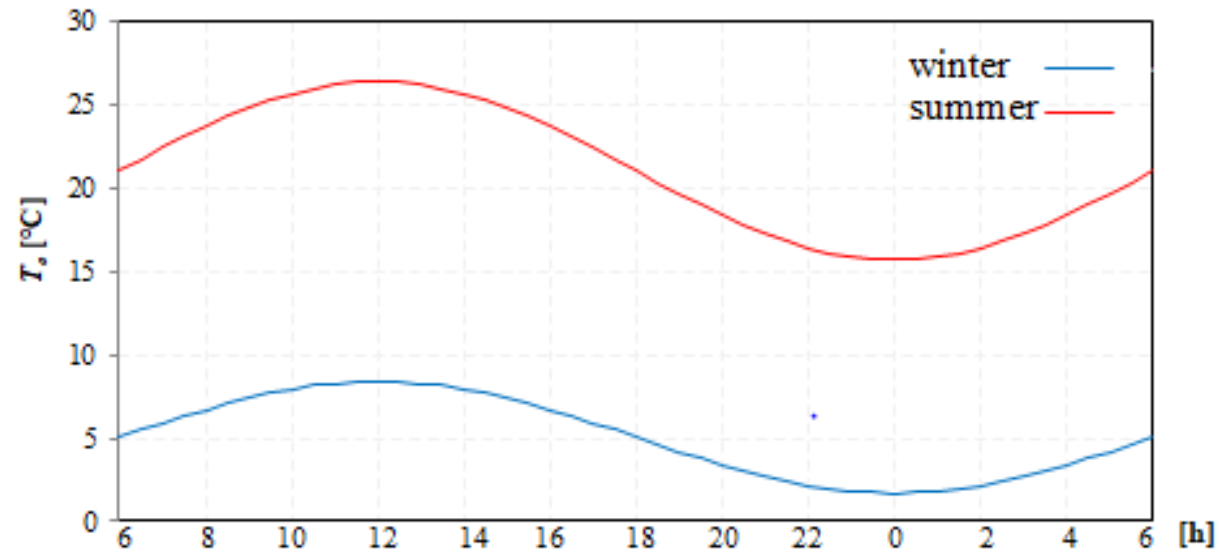

Figure 4: Outdoor temperature variation imposed in the "outdoor" climatic room.

For the indoor temperatures $T_{i}$, we have to fix the temperature variation because the dynamic thermal behaviour of the climatic chamber is not representative of a standard building behaviour. Furthermore, we cannot simulate the behaviour of the building constructed with these blocks as that is what we are studying. We have to simulate the "natural deviation" of the indoor temperature by imposing the daily variation: in winter, we assume constant temperature with night set point reduction and we assume a sinusoidal variation in summer by considering a fixed temperature phase shifting and damping (see Fig. 5). The relative humidity set points are always fixed at 50\% indoors and outdoors except in winter outdoors where the set point is fixed at $90 \%$. 


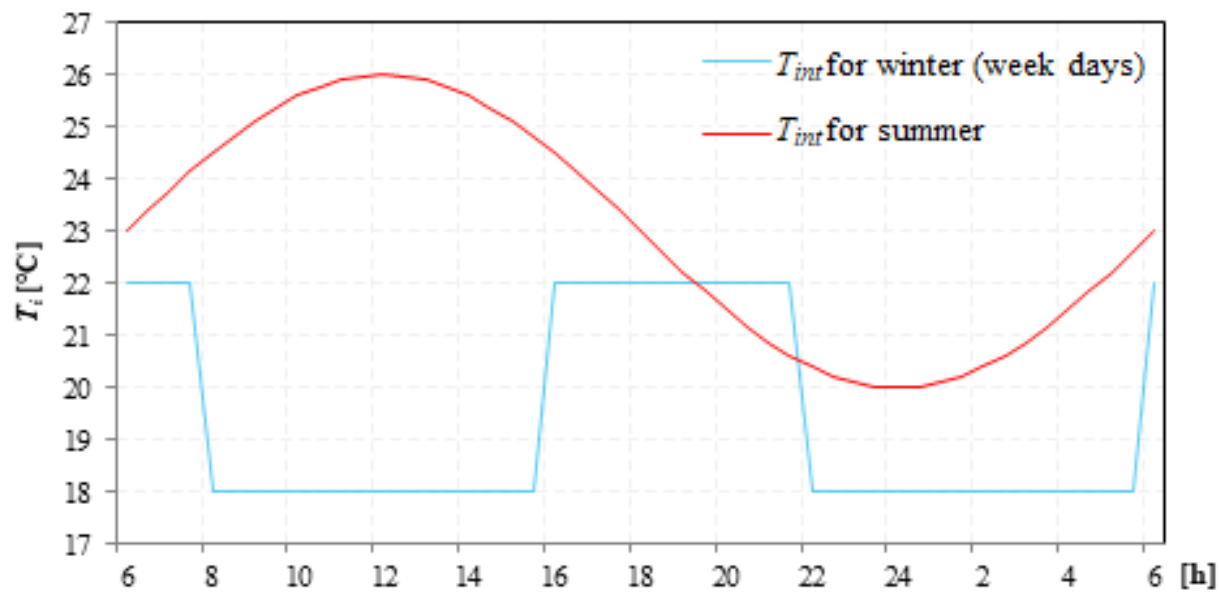

Figure 5: Indoor temperature variation imposed in the "indoor" climatic room.

The aim is to test the wall sample under realistic conditions we can easily found in standard cases. The accuracy of these values is not important here, we just want to avoid extreme conditions or unrealistic conditions. Next, a wall sample was constructed using a commercial block reference shown in Fig. 1 (CLIMAmur 36 reference). Each construction follows the best practices that would be applied on a real building site (mortar, glue, joint, plaster: coating or plasterboard) (see Figure 7). Some authors have numerically verified the edge effects to check the $1 \mathrm{D}$ heat transfer assumption for in situ tests [26]. To verify there are not edge effects, the wall integrates two instrumented blocks: one in the centre and one on a boundary. Infrared thermography was also used. Each of these two blocks integrates $8 \mathrm{~K}$-type thermocouple probes along their thickness in addition of a thermocouple probe located between the plaster coating or plasterboard and the block. Then, we add on the inner face a global (convection + radiation) heat flux sensor, a radiative heat flux sensor and K-type thermocouple surface probes (see Fig. 6 and 7) and another K-type thermocouple surface probe on the outer face. The heat flux sensors are based on a calibrated double T-type thermocouple measuring a temperature difference through a thin copper element. We used radiative and global (convective + radiative) heat flux sensors to assess the mean convection coefficients over the wall sample.

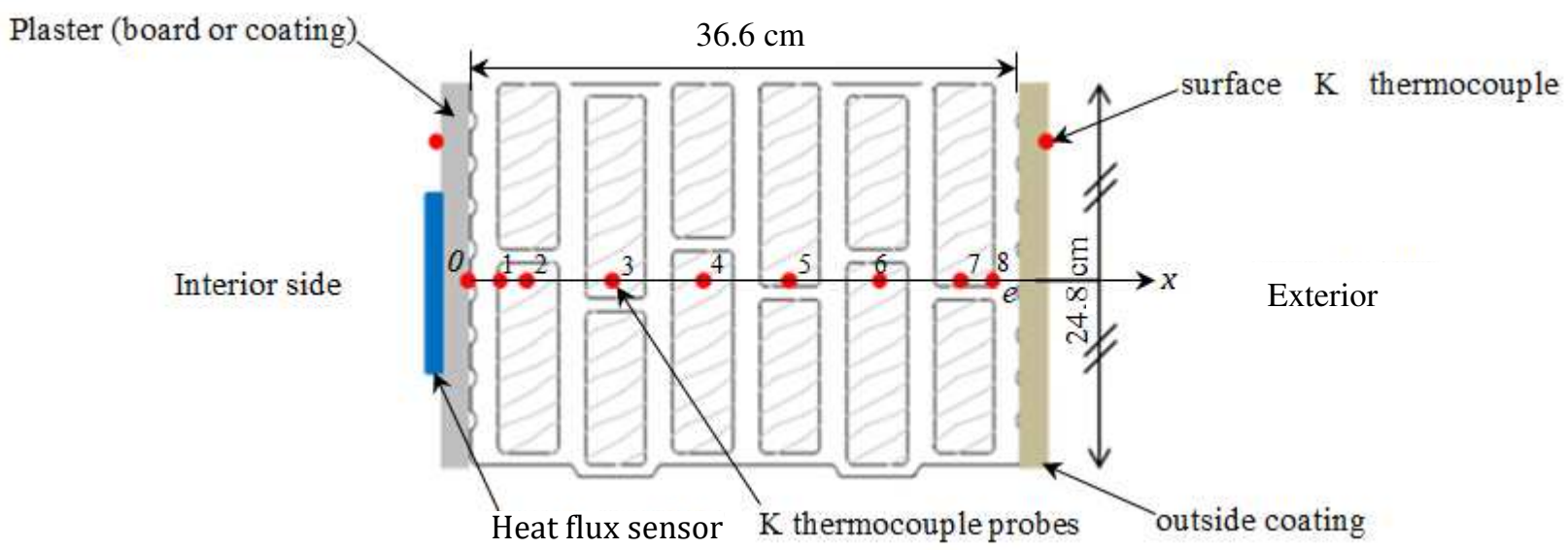

Figure 6: Sensors locations. 


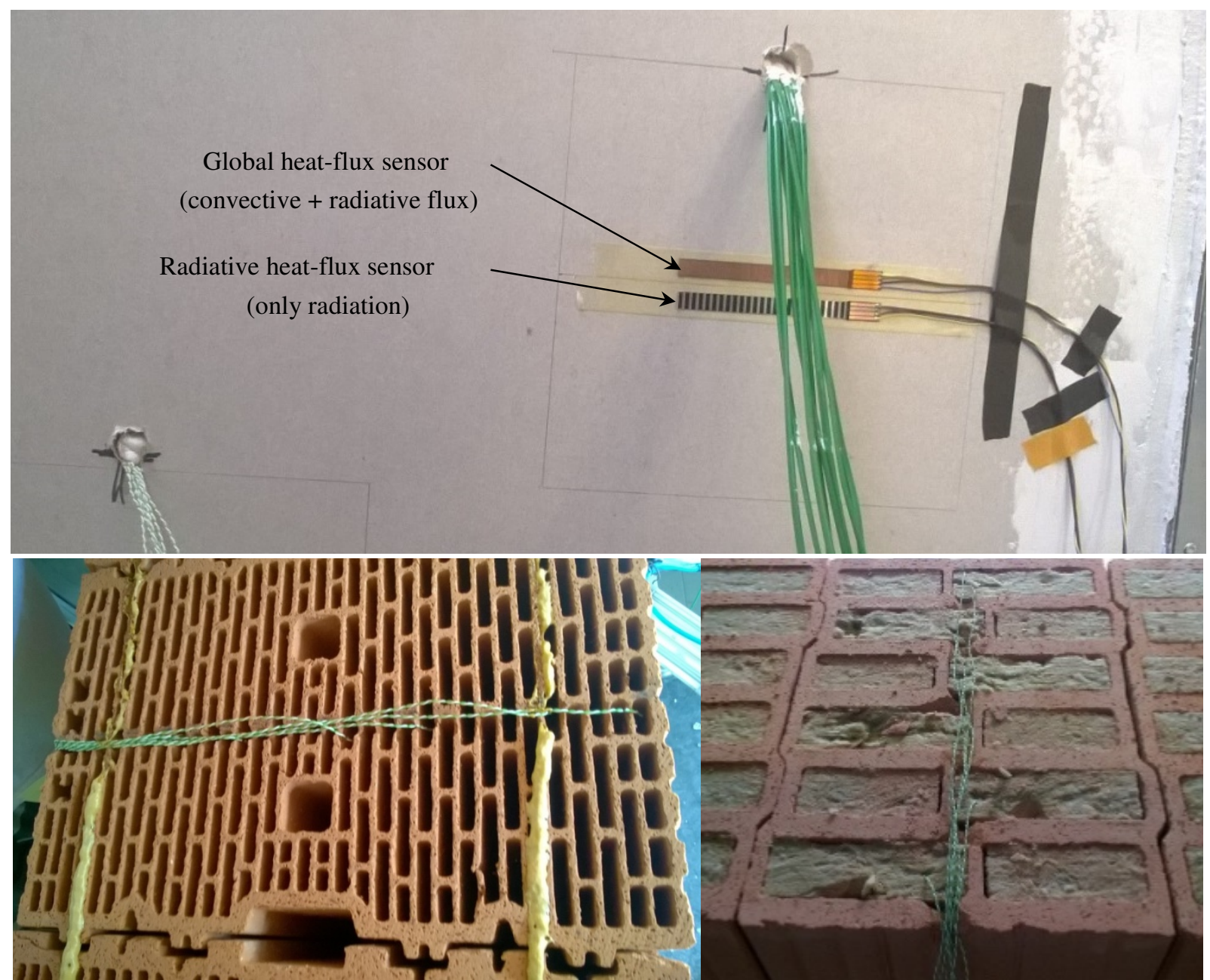

Figure 7: Wall sample, thermocouples and heat-flux transducers locations (plasterboard case).

We have summarised the technical metrology data in Table 1 and the experimental setup in Figure 8:

Table 1: Sensor specifications.

Metrology

\begin{tabular}{cccc}
\hline Quantity & Technology & Range & Uncertainty \\
\hline Temperature & type-K thermocouple (K-TC) & $-75-150{ }^{\circ} \mathrm{C}$ & $\pm 0.8 \mathrm{~K}$ \\
Flux density & double type-T thermocouple (T-TC) (Captec) & $-\infty-\quad+\infty$ & $\pm 3 \%$ \\
\hline
\end{tabular}

Acquisition devices

\begin{tabular}{cc}
\hline Device & Reference \\
\hline Nano voltmeter (for heat flux sensors) & Keithley 2182 A \\
Acquisition module & NI CompactDAQ \\
& + NI-9211 modules
\end{tabular}

All the thermocouples were calibrated before each experiment using a thermal sensors calibration bath in the range: 0 to $100{ }^{\circ} \mathrm{C}$. The heat flux sensors were systematically new and were calibrated by the manufacturer by guarded hot plates. 


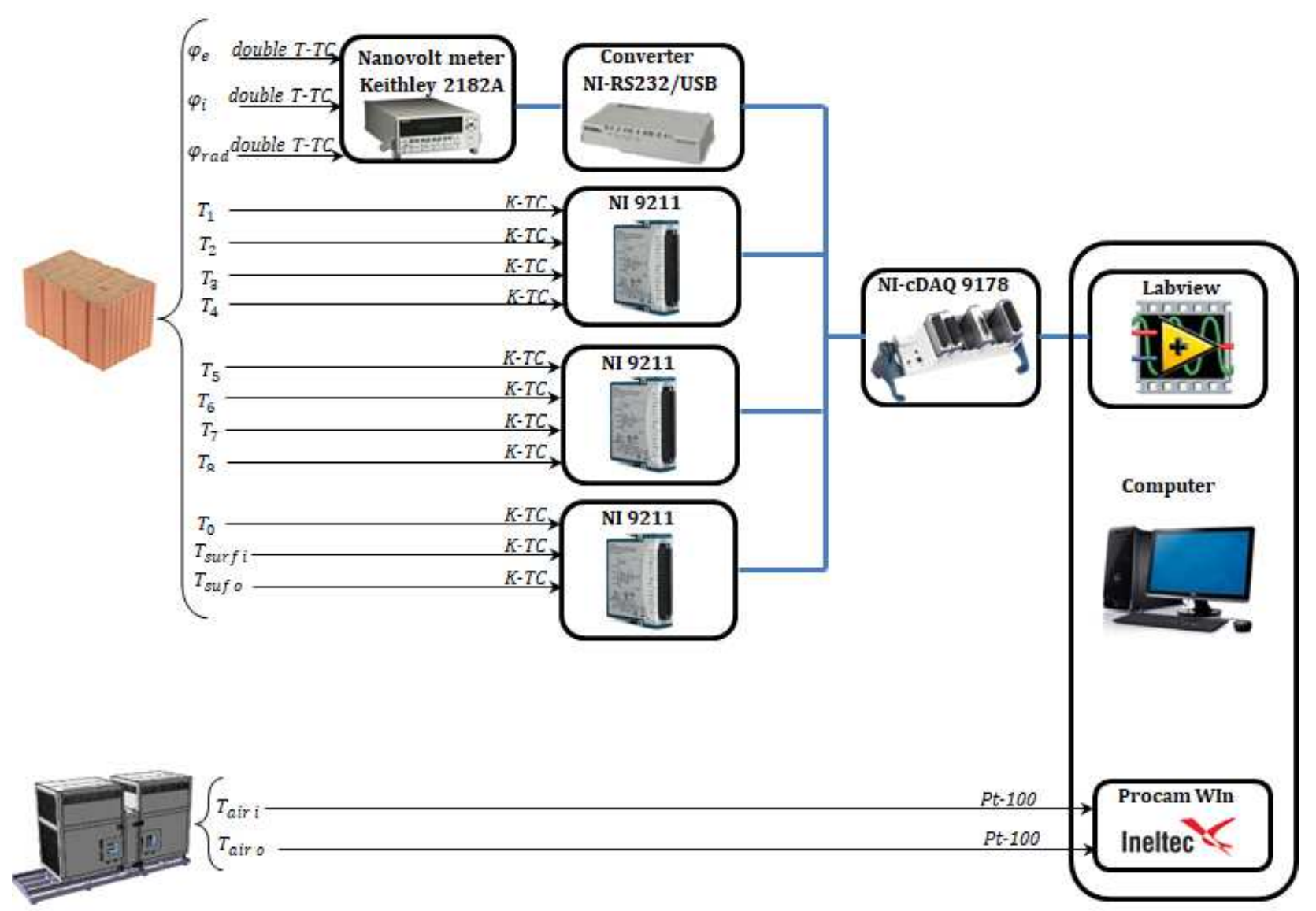

Figure 8: Test bench experimental set up.

\subsection{D finite difference model}

In parallel, an unsteady state 1D finite difference model was performed to emulate the thermal behaviour of this kind of integrated insulation clay hollow blocks considering the heat equation for an homogenous material (see Eq. 1). A $2 \mathrm{~mm}$ homogeneous spatial step $\Delta x$ was used. We give for example on equations 2 and 3 , the discretized formula used in a central cell and on a boundary cell (inner face) by considering a time step $\Delta t$ of $30 \mathrm{~s}$ and an implicit scheme:

$$
\begin{array}{cc}
\rho_{e q} c_{p e q} \frac{\partial T}{\partial t}=\lambda_{e q} \frac{\partial^{2} T}{\partial x^{2}} & \\
T(x, t)=\frac{T(x, t-\Delta \mathrm{t})+F o(T(x-\Delta \mathrm{x}, t)+T(x+\Delta \mathrm{x}, t))}{1+2 F o} & \text { with } F o=\frac{\lambda_{e q}}{\rho_{e q} c_{p e q}} \frac{\Delta t}{\Delta x^{2}} \\
T(x, t)=\frac{T(x, t-\Delta \mathrm{t})+2 F o\left(T(x-\Delta \mathrm{x}, t)+B i T_{i}(t)\right)}{1+2 F o(1+B i)} & \text { with } B i=\frac{h \Delta x}{\lambda_{e q}}
\end{array}
$$

The model includes the plaster coating on the inner and outer faces.

\subsection{Steady state tests}

The first procedure is to experimentally confirm the value of the equivalent thermal conductivity $\lambda_{e q}$ of these blocks based on steady state heat flux measurements. Based on the geometry of the blocks (thickness $e$ ) and the mean flux density output from the heat flux sensor $\bar{\varphi}$, we can compute the equivalent thermal conductivity and compare it to manufacturer's data (see Eq. 3): 


$$
\lambda_{e q}=\frac{e}{\frac{\Delta T}{\bar{\varphi}}-\frac{1}{h_{i}}-\frac{1}{h_{e}}} \text { with } h_{i}=h_{e}=h=22.5 \mathrm{~W} \cdot \mathrm{m}^{-2} \cdot \mathrm{K}^{-1}
$$

It should be notes that the surface heat exchange coefficients $h_{i}$ and $h_{e}$ have been previously determined by specific tests [27]. They are intrinsic to the chamber and cannot be modified (it's linked to the geometry and the internal ventilation system that aims to mix the air to obtain a uniform temperature in the climatic chamber). This operation generates high convection coefficients compared to classical indoor applications but are suitable for outdoor conditions.

\subsection{Unsteady state tests}

A wall sample of $1 \mathrm{~m}^{2}$ is built in the sample holder of the guarded hotbox according to the best practices (mortar application, staggering/stacking). A central block is equipped with temperature sensors, and heat flux sensors on the inner face (see Fig. 6 and 7). Dynamic boundary conditions are applied to the 2 climatic chambers to determine the dynamic thermal properties: $\rho_{e q}$ and $c_{p e q}$ values. We only considered one parameter: the volume heat capacity: $\rho_{e q} \cdot c_{p e q}$ in $\mathrm{J}^{-\mathrm{m}^{-3}} \cdot \mathrm{K}^{-1}$ to simplify the identification procedure to only one term like Zukowski et al. did [18 ] because we can easily compute the apparent density that we assume equal to the apparent density (mass of a block divided by the block volume). Finally, with this hypothesis, the equivalent heat capacity $c_{p e q}$ is the only unknown dynamic parameter. The procedure for determining this equivalent parameter is described on Fig.9. The control of the phase shift and damping is a final qualitative control to avoid inconsistent results.

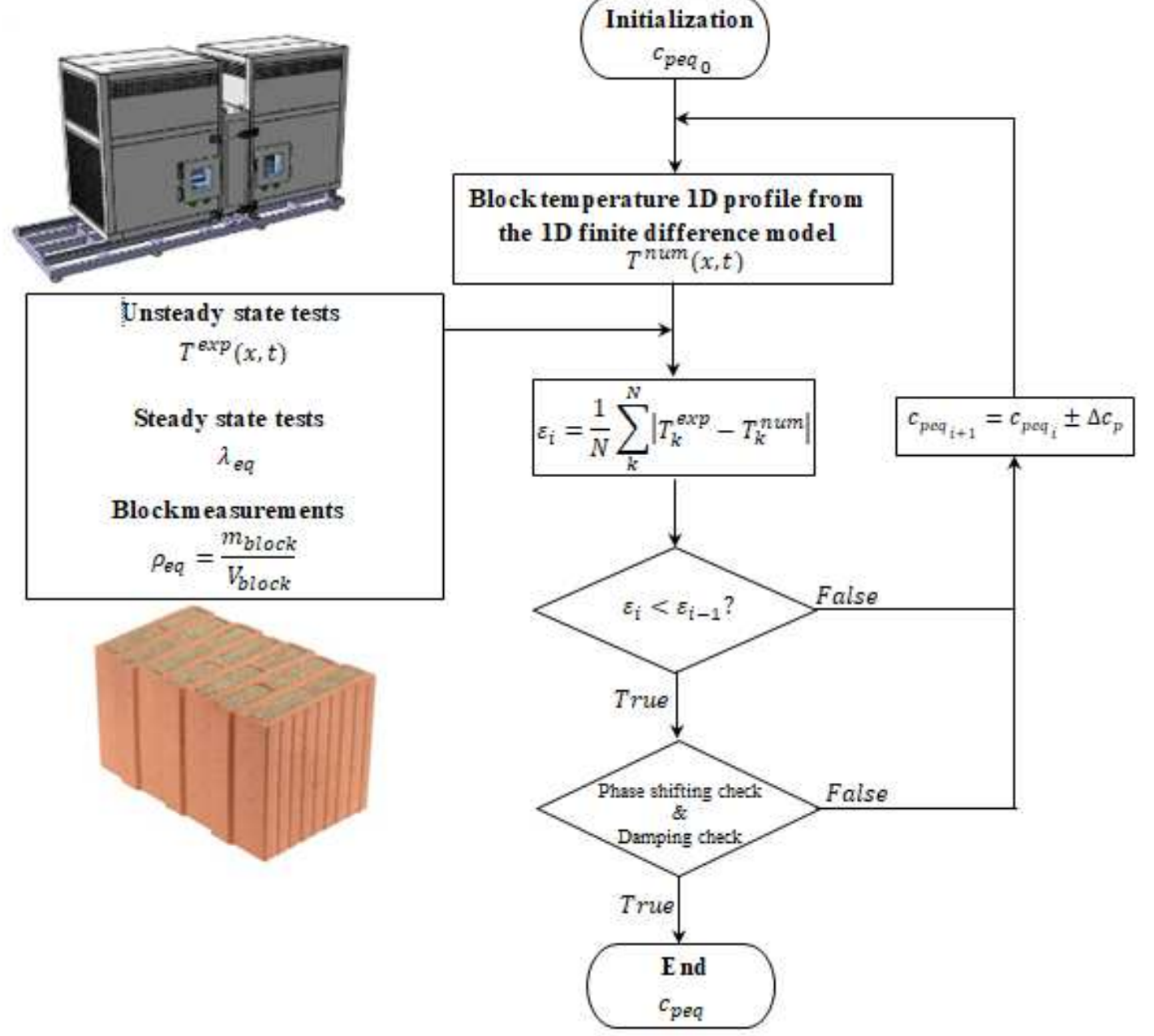

Figure 9: Parametric process flow chart to find equivalent thermal properties. 


\subsection{TRNSYS simulations}

TRNSYS is a robust and powerful building energy simulation software that was chosen to simulate the thermal behaviour of the tested building because this tool can calculate many outputs in addition to the classical ones (air temperature and heating and cooling loads) such as heat flow through the walls and wall temperature, which can be compared with the outputs of heat flow sensors and thermocouples. Once the thermal properties have been identified, a second procedure has been implemented. The objective is to evaluate the dynamic thermal behaviour provided by these blocks. This evaluation is done in two steps. The first step is a TRNSYS simulation of an existing building in order to calculate the interior surface temperatures, air temperatures and thermal comfort. In the second step, an in situ test was carried out to calibrate the TRNSYS model and verify the dynamic behaviour of these blocks in real conditions. A real project was chosen: a residential building built only with CLIMAmur 36 blocks in the Grand-Est Region (North-East of France) (see Fig. 10).
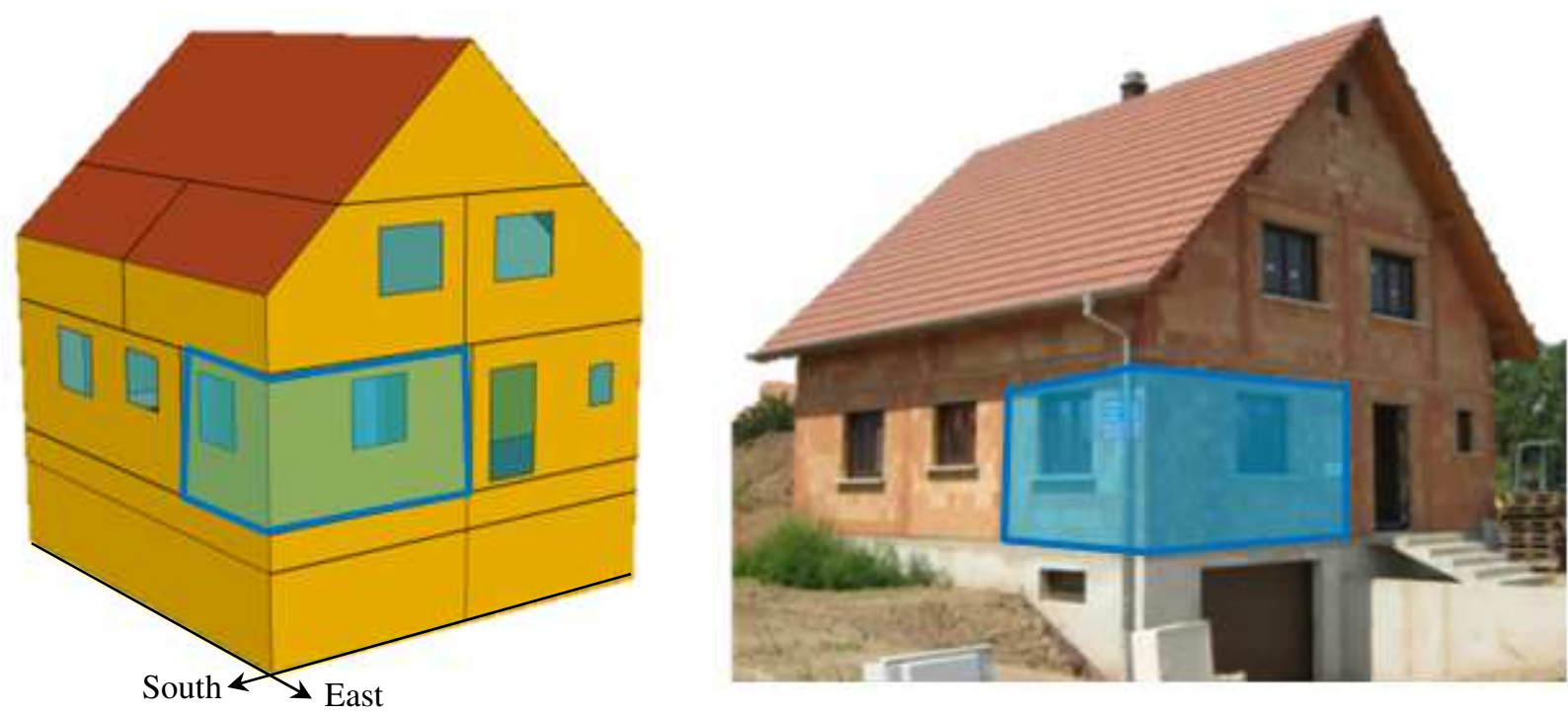

Figure 10: Studied residential building perspective (TRNSYS 3D on left with instrumented room in blue).

\section{6. in situ test}

For the in situ tests, a specific room with a double exposure: East and South was instrumented (see Fig. 10 highlighted in blue). Obviously, it would have been more interesting to test several rooms and even several buildings, but the number of instrumented rooms was voluntarily limited due to the limitation of available sensors (mainly heat flux sensors and only one weather station) and to limit the discomfort for the inhabitants (heat flux sensors and TC probes glued to the wall and TC suspended). Moreover, it is also complicated to find volunteers and suitable buildings. The measurements devices are presented in Table 2 . The locations of the sensors are shown in Fig. 11. The heat flow sensors are located in the middle of the wall to avoid edge effects and the suspended air temperature sensors are located in the middle of the room at a height of $1.5 \mathrm{~m}$. A radiation shield around the sensor (tube with low emissivity coating) allows only air temperature to be measured.

Table 2: In situ test sensors and data logger specifications.

\begin{tabular}{llll}
\multicolumn{1}{c}{ Device } & \multicolumn{1}{c}{ Type } & \multicolumn{1}{c}{ Sensibility } & \multicolumn{1}{c}{ Accuracy } \\
\hline Temperature probes & T thermocouples & - & $\pm 0.1 \%+0.5^{\circ} \mathrm{C}$ \\
Data logger & GRAPHTEC midi LOGGER GL220 & $1 \mu \mathrm{V}$ to $0.01 \mathrm{~V}$ & $\pm 0.1 \%$ \\
Heat Flux sensors & double T-Thermocouples $($ Captec $)$ & $170 \mu \mathrm{V} /\left(\mathrm{W} / \mathrm{m}^{2}\right)$ & $\pm 3 \%$ \\
Weather station & Davis Pro Vantage2 & & -
\end{tabular}






Figure 11: First floor plan with sensor and weather station locations.

\section{Results}

\subsection{Edge effects}

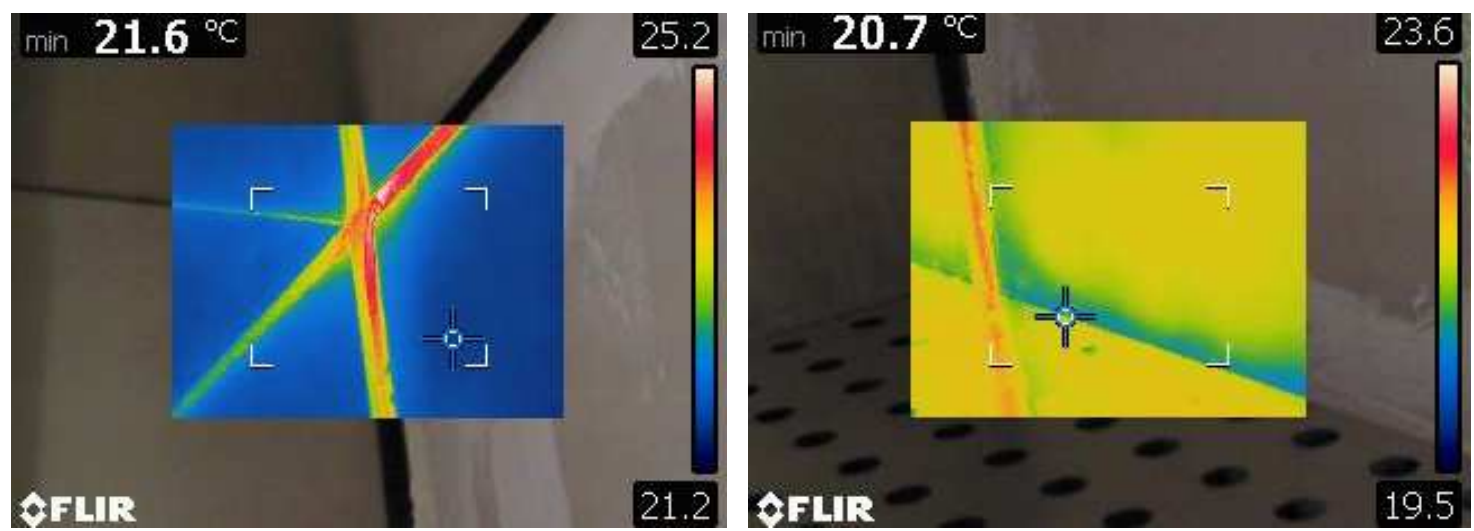

Figure 12: Infrared pictures of the inner face corners during a test.

To check the influence of edge effects, we used an infrared (IR) camera (FLIR T450sc: range -15 to $70{ }^{\circ} \mathrm{C}$ and NET noise equivalent temperature of $0.03 \mathrm{~K}$ ). Its high sensitivity (NET) allows the detection of very small temperature differences. The camera was placed on a tripod inside a climate chamber during operation, at a distance of about $50 \mathrm{~cm}$ from the wall. By analysing the images from the IR camera, we were able to check the impact of edge effects (see Fig. 12) which show that these are insignificant. Indeed, we can clearly see that on the plasterboard the colour is homogeneous which means that the heat transfers occur uniformly on the wall, the edge effects being well concentrated only on a few centimetres of the outer frame of the wall. This assumption of 1D transfer over a short surface is also shown numerically by Roque et al [26] for solid walls and in situ tests. 


\subsection{Steady state tests}

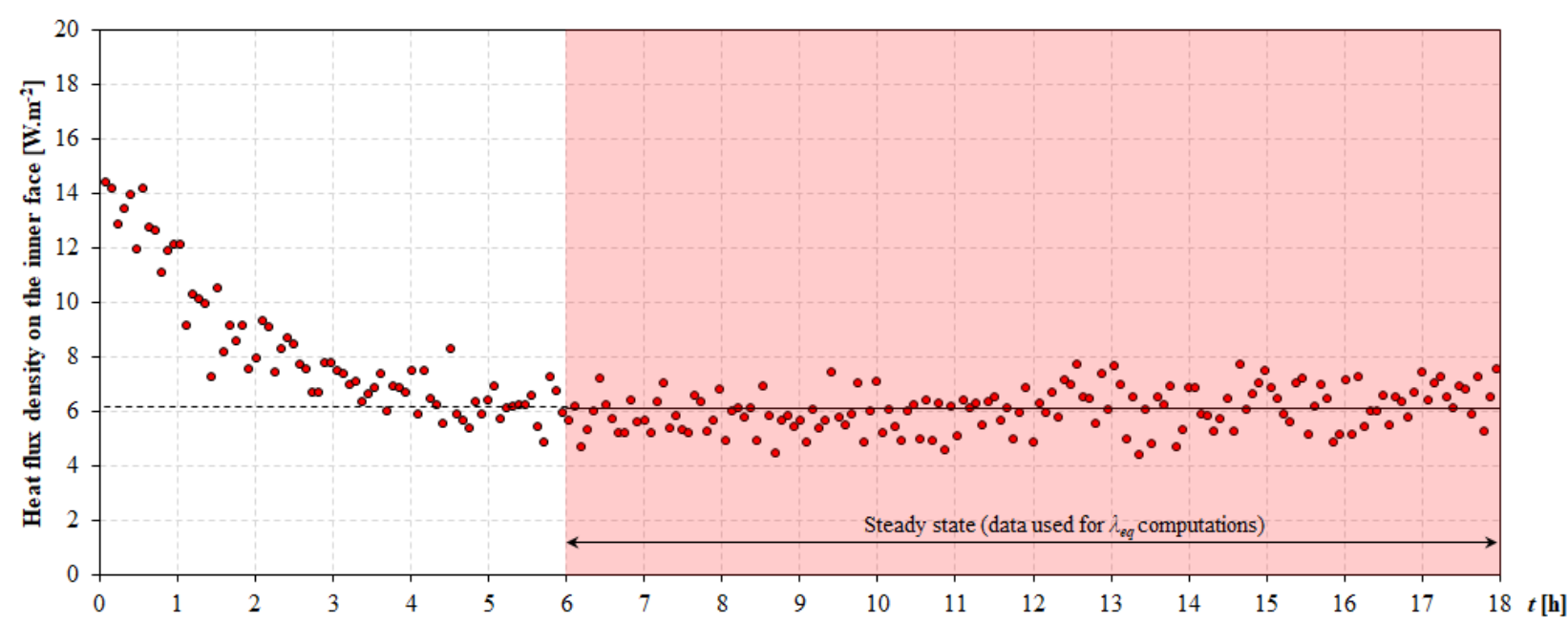

Figure 13: Steady state test results for $\lambda_{\text {eq }}$ identification (mean values over $5 \mathrm{~min}$ ).

We applied the same experimental method used by many authors $[16,17,26]$ to evaluate the equivalent thermal conductivity or thermal resistance of clay hollow blocks. We carried out an 18-hour test in which we imposed a constant temperature difference between the inner and outer chambers $(30 \mathrm{~K})$. The temperature set points were kept constant in the climate chambers $\left(20^{\circ} \mathrm{C}\right.$ for the indoor chamber and $-10{ }^{\circ} \mathrm{C}$ for the outdoor chamber). Then, based on the average filtered flux density over the steady-state period $\bar{\varphi}$ we calculated the equivalent thermal conductivity and compared it to the manufacturer's data (see Eq. 4, Fig. 13 and Table 3). The filter is a moving average performed over 10 minutes.

Table 3: Equivalent thermal conductivity of CLIMAmur 36 bricks.

\begin{tabular}{cccc}
\multirow{2}{*}{ Thermal conductivity } & \multicolumn{3}{c}{ CLIMAmur 36 } \\
\cline { 2 - 4 } & Test & Manufacturer data & Deviation \\
\hline$\lambda_{e q}\left[\mathrm{~W} . \mathrm{m}^{-1} \cdot \mathrm{K}^{-1}\right]$ & 0.0750 & 0.0785 & $-4.5 \%$
\end{tabular}

The equivalent thermal conductivity is very close to the manufacturer's data and will be considered as validated. We retain an equivalent thermal conductivity of $0.08 \mathrm{~W} \cdot \mathrm{m}^{-1} \cdot \mathrm{K}^{-1}$ for the CLIMAmur36 block. Secondly, we note a high variability in the heat flux measurements (sampling rate of $10 \mathrm{~s}$ ) like the experimental results of Faye et al. [15]. It can be explained mainly by the high turbulence in the chamber which generates this phenomenon and by the small surface of the heat flux sensor which tends to increase its sensitivity. However, Faye et al [15] have shown that filtering the data provides relevant and reliable results. Larger heat flux sensors (10 times larger) used in other tests for other applications generated smoother curves but equivalent results to the filtered data. By smoothing the data over a few minutes, we obtain a stable trend that leads to the calculation of the equivalent thermal conductivity.

\subsection{Unsteady state tests vs $1 \mathrm{D}$ model}

We start by using the tabulated data given in the French standard [1] for each elementary material: mineral wool, plaster and clay to compare the numerical model with the dynamic laboratory tests (see Table 4). As a first step, we verified that the conductive heat transfers in the initial 2D geometry could be assimilated to $1 \mathrm{D}$ heat transfers. A 2D finite difference model in the unsteady regime (integrating the outer and inner plaster coating) was programmed and shows that the isothermal lines are comparable to parallel and perpendicular 
lines at the boundaries, which justifies the assumption of 1D thermal diffusion (see Fig. 14). The influence of internal thermal bridges is therefore negligible from the point of view of the direction of thermal conduction. The simplification to the 1D model is therefore relevant. This result is similar to the work of Zukowski et al [18] who show the validity of considering 1D heat transfer for a hollow clay block filled with perlite.

Table 4: Thermal properties blocks component materials.

\begin{tabular}{ccccl} 
& Clay & Wool & Plaster & \\
\hline$\rho$ & 1540 & 50 & 744 & $\mathrm{~kg} \cdot \mathrm{m}^{-3}$ \\
$c_{p}$ & 700 & 1030 & 1008 & $\mathrm{~J} \cdot \mathrm{kg}^{-1} \cdot \mathrm{K}^{-1}$ \\
$\lambda$ & 0.41 & 0.035 & 0.21 & $\mathrm{~W} \cdot \mathrm{m}^{-1} \cdot \mathrm{K}^{-1}$
\end{tabular}

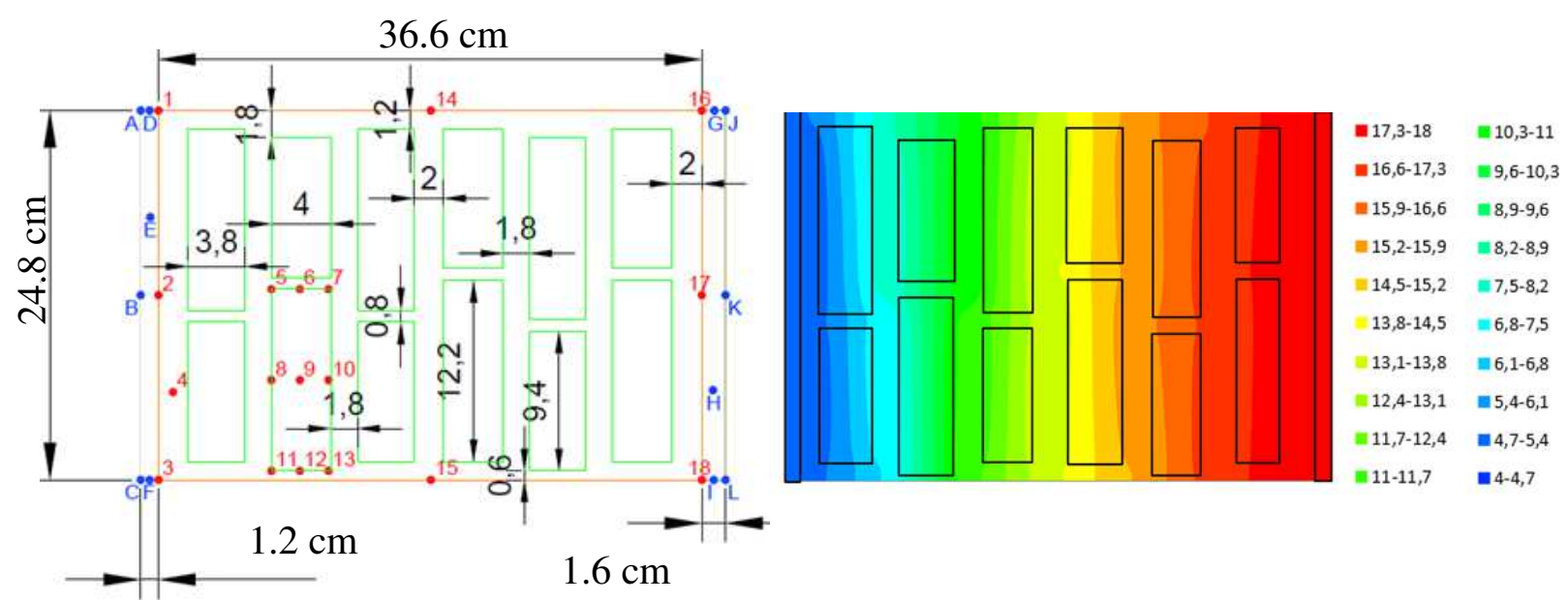

Figure 14: Simplified Cartesian geometry model and isothermal lines from the 2D finite difference model.

Secondly, we calculated a volume-weighted average of the volume heat capacity (see Eq. 5) as done by some authors $[14,16,17]$.

$$
\rho c_{\text {peq }}=\frac{V_{\text {wool }}\left(\rho c_{p}\right)_{\text {wool }}+V_{\text {clay }}\left(\rho c_{p}\right)_{\text {clay }}}{V_{\text {tot }}}=506400 \mathrm{~J} \cdot \mathrm{m}^{-3} \cdot \mathrm{K}^{-1}
$$

Then we used this weighted average in the 1D model and it generated curves that were inconsistent in terms of dynamics (temperature phase shift and damping) with the experimental data. Applying this value into the TRNSYS simulations also generated results that were inconsistent with the measurements. It is quickly noticed that the "real" equivalent volumetric heat capacity $\left(\rho . c_{p}\right)_{\mathrm{eq}}$ is lower than expected. A parametric study was then launched using a least squares method on both the complete 8 thermocouple data (as Zukowski et al. [18]), the damping values and the phase shift values in order to identify the equivalent volumetric heat capacity value $\left(\rho . c_{p}\right)_{\mathrm{eq}}$ of these blocks which reaches $269500 \mathrm{~J} \cdot \mathrm{m}^{-3} \cdot \mathrm{K}^{-1}$ at the end of the optimisation process (see Fig. 9). It was important here to take into account the dynamic characteristics in addition to the temperatures to be sure that the experimental sine curves are synchronous with the 1D model and also in terms of damping and temperature phase shift. Therefore, the least squares method was applied on these 3 parameters (temperatures, damping and phase shift for each thermocouple). Figures 15 and 16 compare the outputs of the optimised 1D model with the experimental data (temperatures and flows). The correlation is very satisfactory for the winter configurations. Larger deviations appear for the summer case mainly for thermocouples 7 and 2, but the dynamics are relevant (same damping and phase shift) and with a deviation (about $1 \mathrm{~K}$ ) of the order of magnitude of the sensor uncertainty $( \pm 0.8 \mathrm{~K})$. We found a root mean square error (RMSE) of $0.36 \mathrm{~K}$ for the winter case and $0.45 \mathrm{~K}$ for the summer case (values below the sensor uncertainty) and consider our model as validated. 


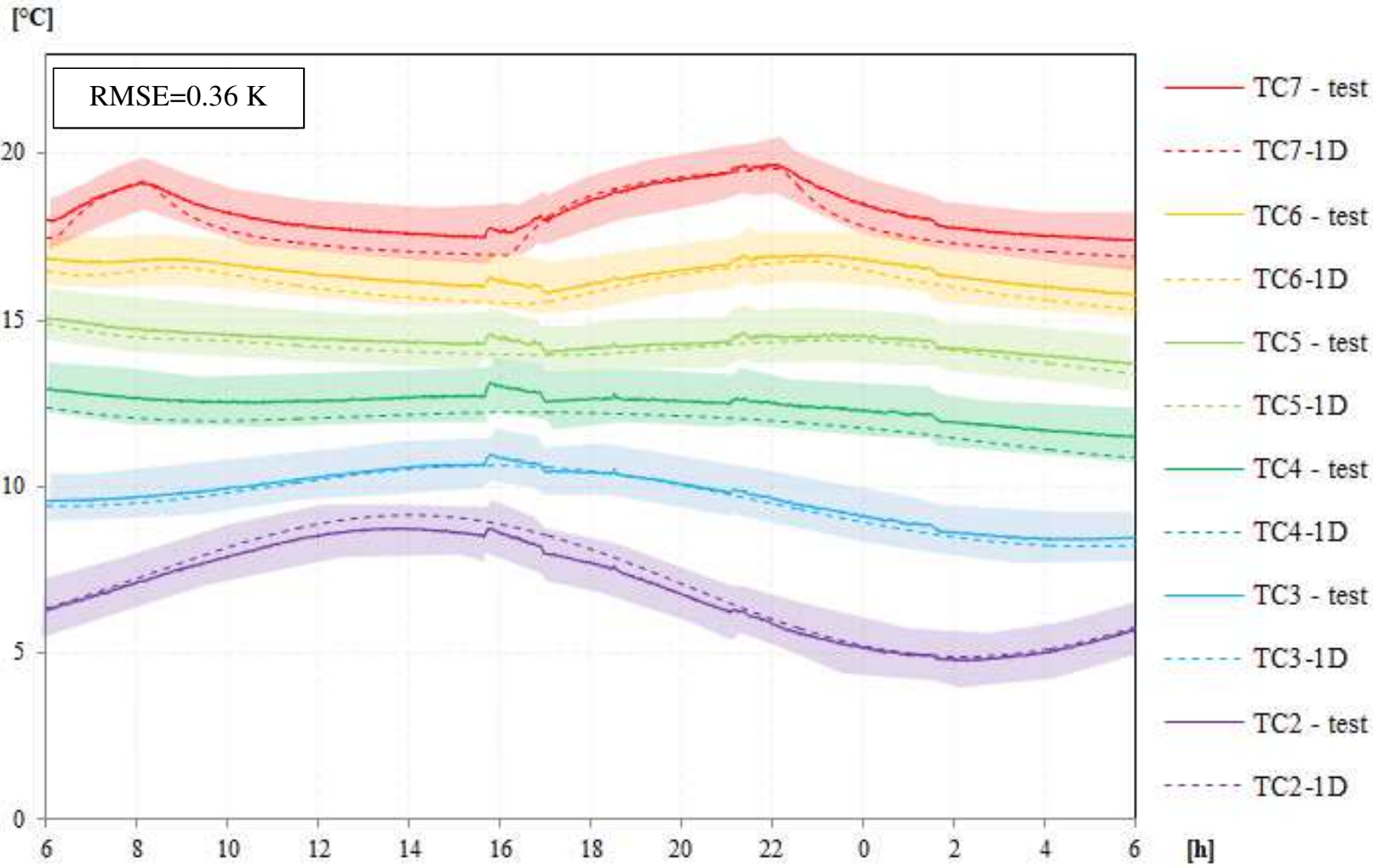

Figure 15: Wall inside temperatures comparison between $1 D$ model and laboratory test (with uncertainty ranges) in winter conditions.



Figure 16: Wall inside temperatures comparison between $1 D$ model and laboratory test (with uncertainty ranges) in summer conditions.

With regard to the dynamic behaviour, it is important to check that the amount of energy entering and leaving the inner wall (heat storage/release) is also consistent. Figures 17 and 18 show these algebraic flux 
densities for the winter and summer cases respectively, comparing the 1D model data and the experimental tests (10 s sampling rate).

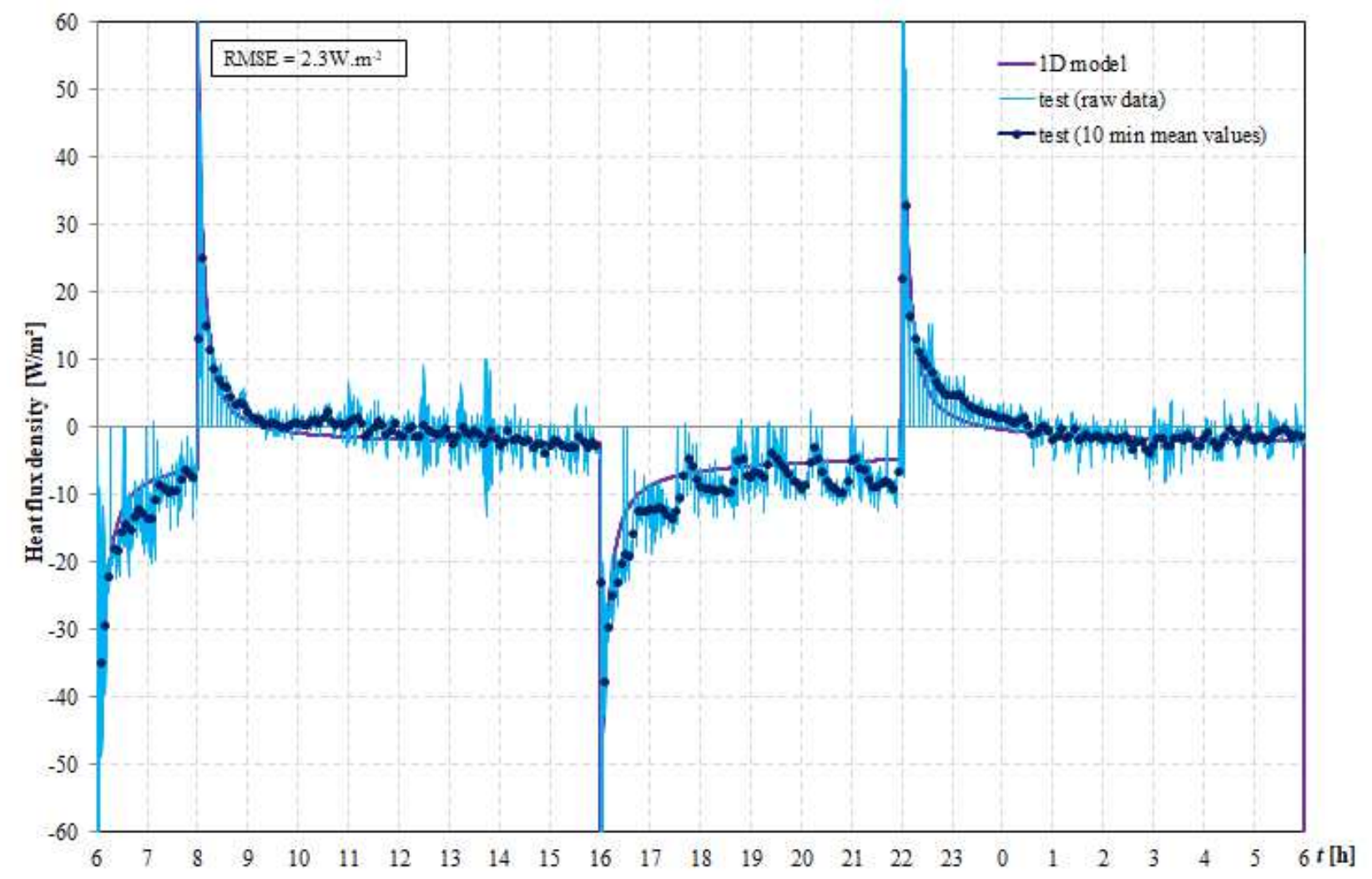

Figure 17: Indoor heat-flux density evolution in winter conditions.

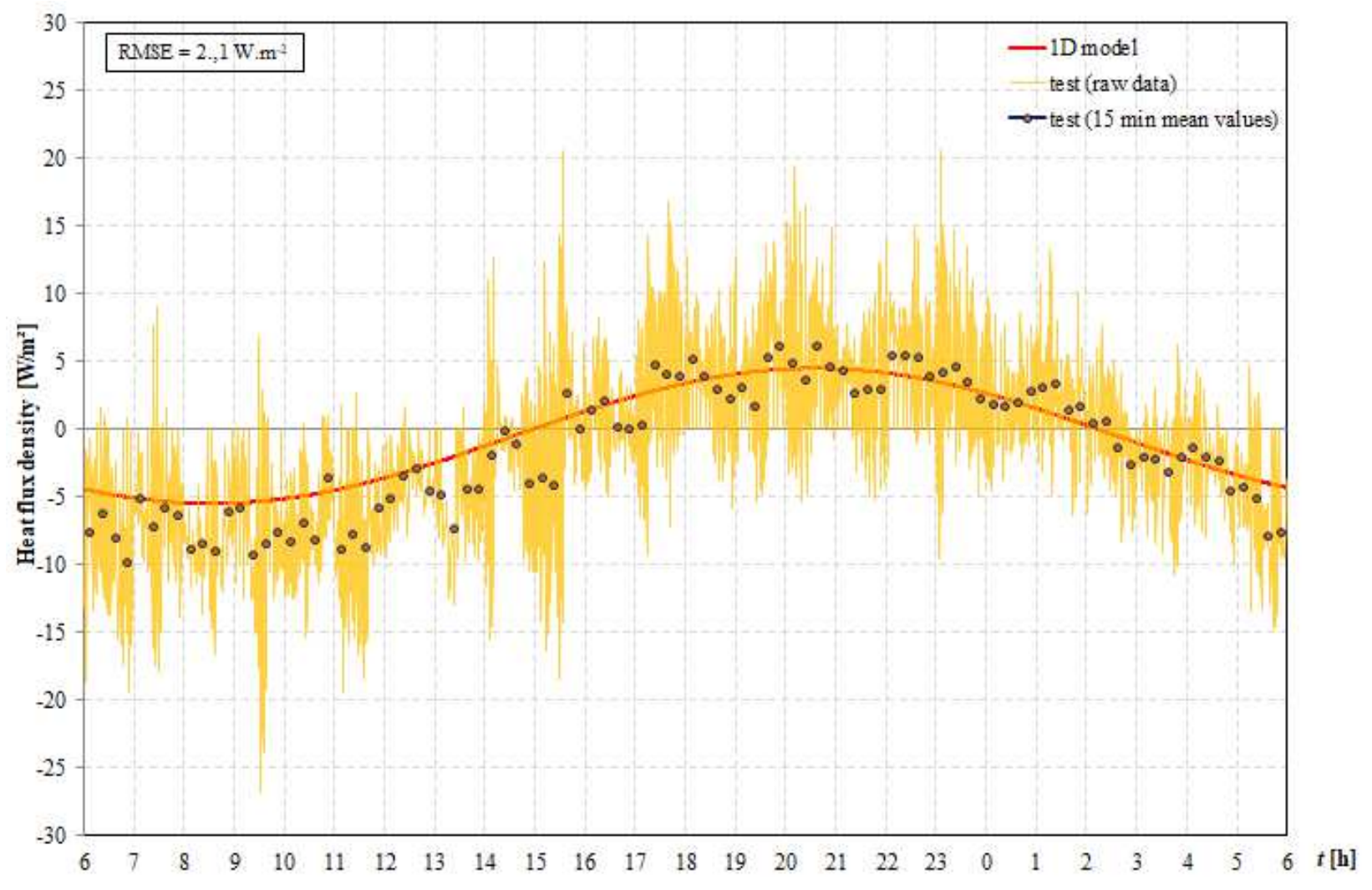

Figure 18: Indoor heat-flux density evolution in summer conditions. 
Statistically, we calculated RMSEs of 2.3 and $2.1 \mathrm{~W} . \mathrm{m}^{-2}$ for the winter and summer cases respectively. We find a good correlation between the simplified 1D numerical model and the experimental results mainly for the winter conditions. In summer, we observe well the storage phase during the day (positive values) and the release phase during the night (negative values). The two average curves considering the average values over 10 minutes (winter case) and 15 minutes (summer case) fit the 1D models well which validates the equivalent properties found. Finally, if conventional values mainly on heat capacities (about $1000 \mathrm{~J} . \mathrm{kg}-1 . \mathrm{K}$ 1) are used in the 1D model, this generates inconsistent results on heat flux densities as well as for wall temperatures.

\subsection{Equivalent thermal properties}

Finally, for the building energy simulations, we will use the following data from Table 5 for each thermophysical property. It should be noted that we use the apparent density data provided by the manufacturer (overall mass of the block divided by the external volume of the brick) to adjust the equivalent heat capacity $c_{p e q}:$

Table 5: Equivalent thermal properties and literature comparison.

\begin{tabular}{ccccc} 
Reference & CLIMAmur 36 & $\begin{array}{c}\text { Zukowski et al. } \\
{[\mathbf{1 8}]}\end{array}$ & $\begin{array}{c}\text { Sala et al. } \\
{[\mathbf{1 7 ]}}\end{array}$ \\
\hline Block type & $\begin{array}{c}\text { Integrated clay hollow } \\
\text { block }\end{array}$ & $\begin{array}{c}\text { Integrated Insulation } \\
\text { clay Hollow block }\end{array}$ & $\begin{array}{c}\text { Clay hollow block } \\
\text { (big cavities) }\end{array}$ & \\
\hline $\begin{array}{c}\text { Insulation } \\
\text { material }\end{array}$ & mineral wool & Perlite & air & \\
\hline$\rho_{e q}$ & 630 & 653 & 632 & $\mathrm{~kg} \cdot \mathrm{m}^{-3}$ \\
$c_{p e q}$ & 430 & 855 & 1041 & $\mathrm{~J} \cdot \mathrm{kg}^{-1} \cdot \mathrm{K}^{-1}$ \\
$\lambda_{e q}$ & 0.08 & 0.09 & 0.21 & $\mathrm{~W} \cdot \mathrm{m}^{-1} \cdot \mathrm{K}^{-1}$
\end{tabular}

The value of $c_{p e q}$ seems to be low compared to classical data [1] or to the results of some authors who found values between 800 and $1000 \mathrm{~J} \cdot \mathrm{kg}^{-1} \cdot \mathrm{K}^{-1}[14,16-18]$. A first, explanation may be that the tabulated values are often default values and therefore uncertain (and possibly wrong) values (about $1000 \mathrm{~J} \cdot \mathrm{kg}^{-1} \cdot \mathrm{K}^{-1}$ for many building materials) [1]. Secondly, some authors have not used periodic thermal loads but unrealistic constant temperature differences as boundary conditions [18] which do not represent realistic loads (sinusoidal outdoor temperature, periodic solar fluxes or periodic cycles of indoor heat storage and release). Some authors also simply use a volume-weighted average without experimental considerations [14, 16]. In addition, it is likely that the thin layer of air between the plasterboard and the hollow clay blocks has a significant impact on these values as it cuts off access to the thermal mass behind. We found the same tendency (low equivalent thermal capacities) for two other references of hollow clay blocks (without integrated mineral wool (see Fig. 1)) with $437 \mathrm{~J} \cdot \mathrm{kg}^{-1} \cdot \mathrm{K}^{-1}$ for the R37 blocks and $475 \mathrm{~J} \cdot \mathrm{kg}^{-1} \cdot \mathrm{K}^{-1}$ for the GF R20 blocks from the manufacturer Wienerberger. On the other hand, for a homogeneous solid material (aerated concrete), we applied the same experimental protocol and found a more consistent but low value of $800 \mathrm{~J}^{\mathrm{kg}} \mathrm{kg}^{-}$ ${ }^{1} \cdot \mathrm{K}^{-1}$ compared to a tabulated value of $1000 \mathrm{~J} \cdot \mathrm{kg}^{-1} \cdot \mathrm{K}^{-1}$. This difference could be explained by the smoother surface condition of solid aerated concrete compared to the rougher surfaces of hollow clay blocks (see Fig. 1) which reduces the adhesion with plaster board and generates a higher contact thermal resistance (larger air cavity). We then decided to study the impact of the air layer created by the glue point to seal the plasterboard to confirm this impact. Finally, the main explanation is linked to the fact that the air layer is not modelled. The finite difference model does not take into account an air layer due to the uncertainty of its thickness and airtightness. In practice it is not modelled in the commercial codes and it is assumed that plasterboards are in contact with the masonry wall. The equivalent thermal properties naturally take into 
account the effect of the air layer which tends to limit access to the thermal mass behind it and ultimately leads to low specific heat capacity values.

\subsection{Influence of the inside coating}

In most cases, integrated insulation clay hollow blocks or simply clay hollow blocks walls are covered on the inside with plaster, which can take two forms: glued plasterboard which creates an unventilated air layer, or plaster coating which adheres perfectly to the surface of the blocks. Figure 19 shows the sample plasterboard wall with the glue points and shows a sample plastered wall.
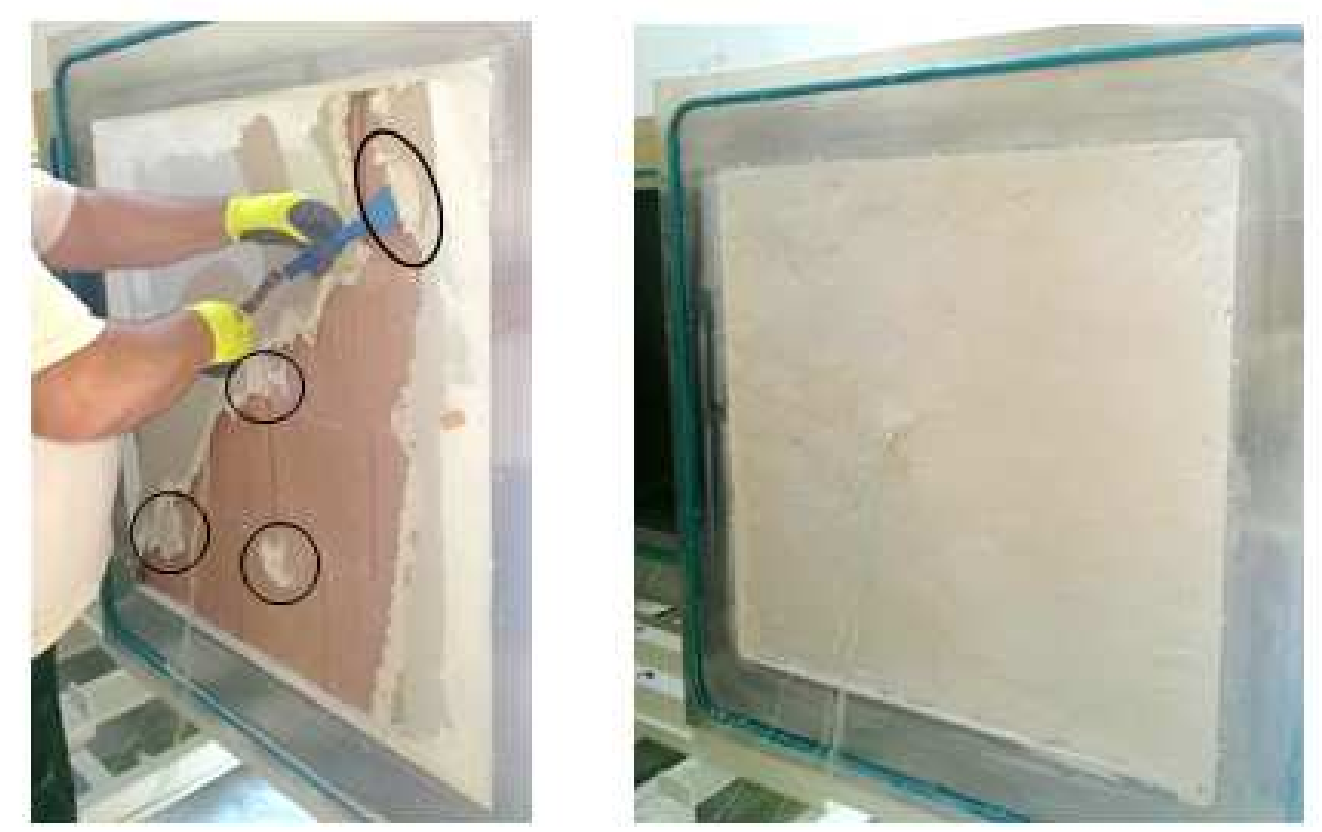

Figure 19:Plasterboard wall sample with glue points highlight (left) and plaster coating wall sample (right).

Usually, integrated insulation clay hollow block walls are mainly covered on the inside with glued plasterboard, as this is the most economical and quickest solution compared to plaster coating which requires long drying times and specific skills. Thermally, the air layer increases the thermal resistance but can partially cut off the access to the rear thermal mass and penalise the dynamic thermal behaviour (lower heat storage/release cycles between the environment and the wall). The previous protocol was applied on these two configurations to study the impact of this additional air layer on the dynamic behaviour of the blocks. We focused on the measured heat flux densities to assess the difference in heat storage and release due to the air layer in unsteady state. Figures 20 and 21 show the variation of the heat fluxes for the two cases under winter and summer conditions. 




Figure 20: Indoor heat-flux density in winter with plasterboard or with plaster coating inside.

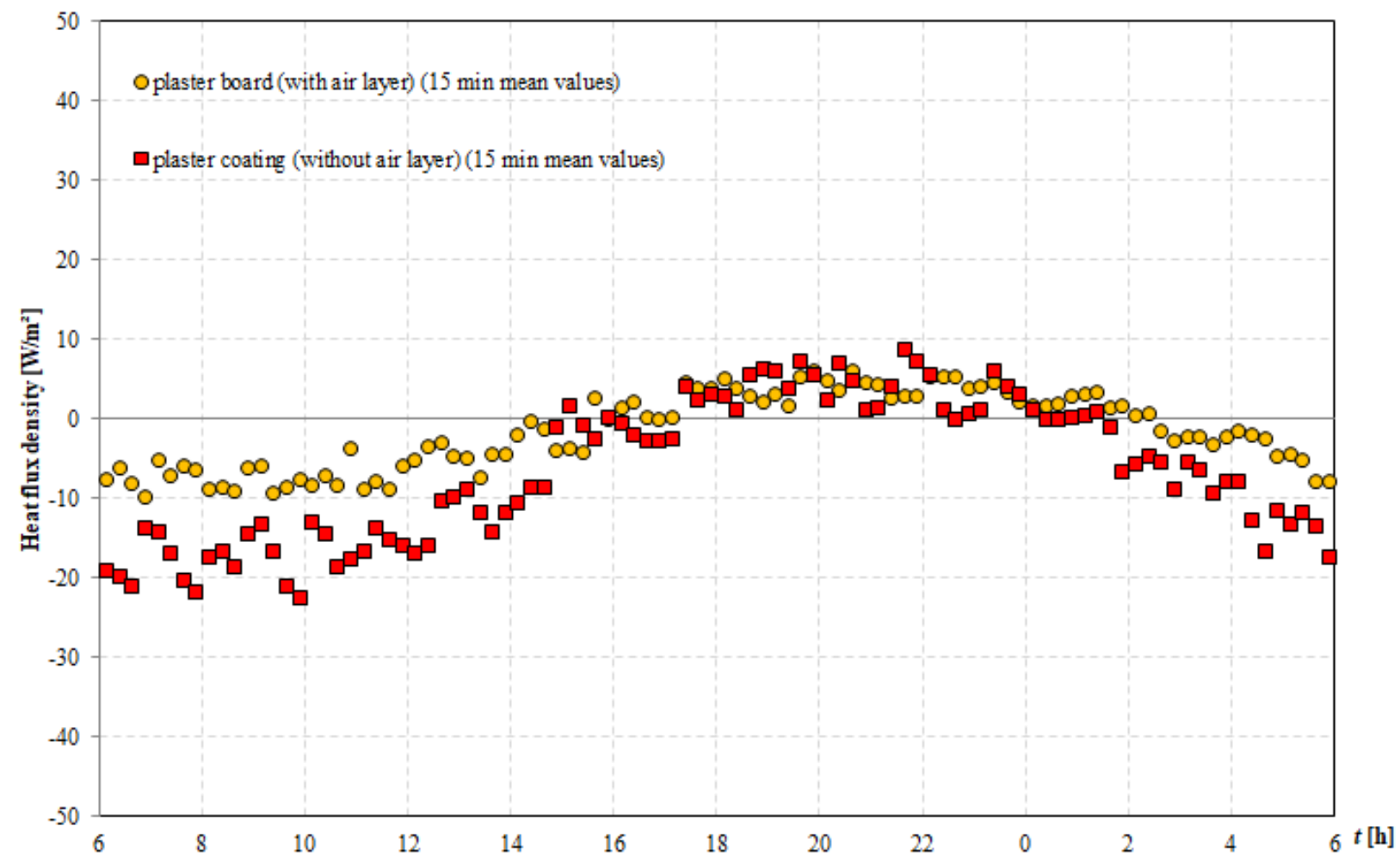

Figure 21: Indoor heat-flux density in summer with plasterboard or with plaster coating inside.

The plaster on the inner face seems to have a significant impact on the dynamic behaviour of the whole wall. Indeed, in winter, the absolute value of the instantaneous flux density in the case of the plasterboard is systematically lower than the value in the case of the plaster coating. The same observation is made for the summer case, where the heat flux damping is slightly lower in the case of plaster board. In Figures 22 and 23 we plot the 5-minute average data from the plaster test against the 5-minute average data from the plasterboard test. We clearly see a heat flux reduction factor that is similar for each seasonal test. 


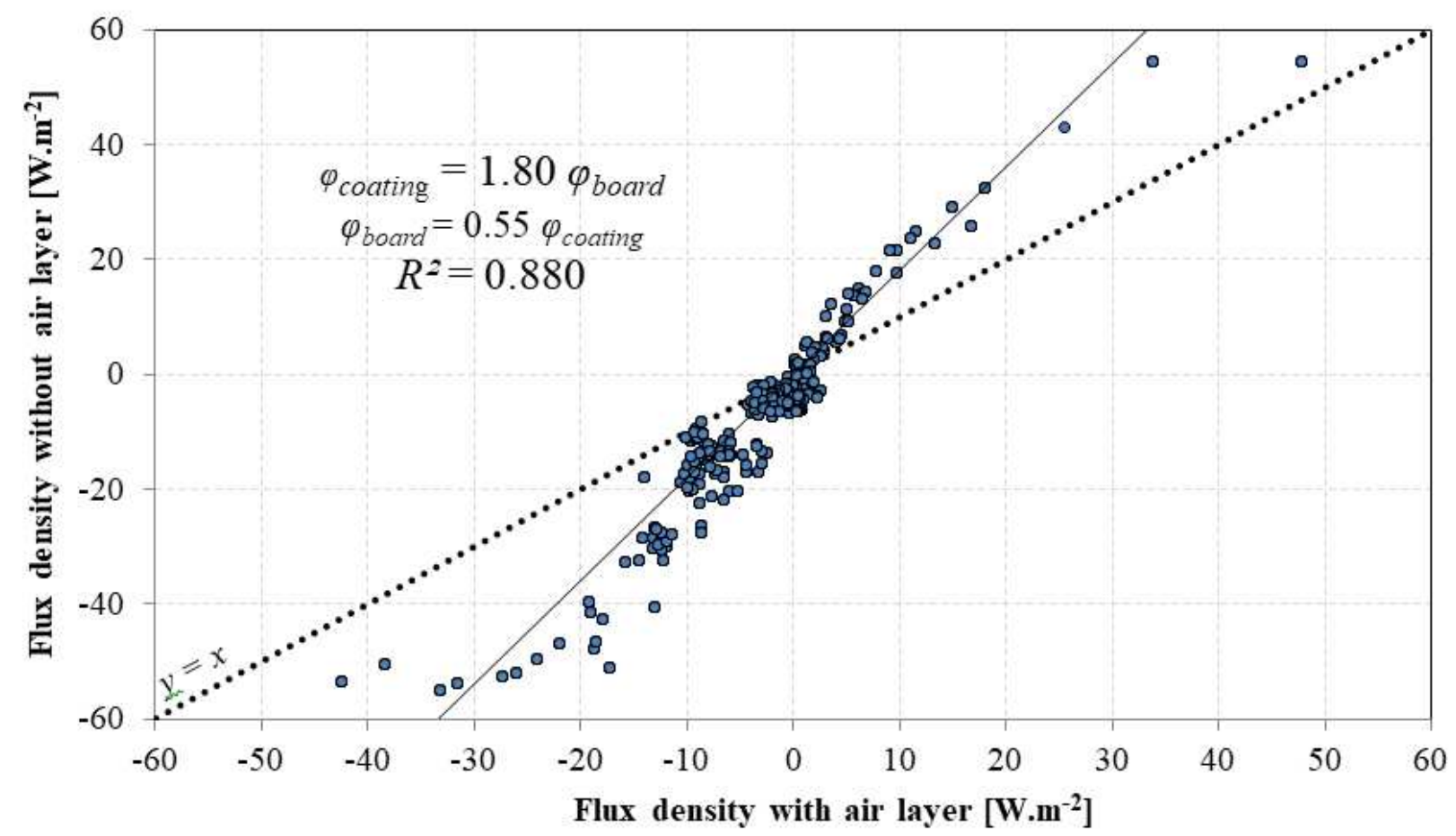

Figure 22: Indoor heat-flux density factor reduction between plasterboard case and plaster coating case in winter conditions.



Figure 23: Indoor heat-flux density factor reduction between plasterboard case and plaster coating case in summer conditions.

In both cases, the reduction factor is close to 55\%, which reduces the heat storage or release in the wall in the same ratio. From the overall thermal resistance and steady state point of view of, this air layer is beneficial as it contributes to improve the thermal insulation capacity, but this increase is infinitesimal (about $-1 \%$ on the equivalent thermal conductivity) compared to the significant decrease of the effective thermal mass (-55\% on the stored/released heat flux). Finally, the relatively low equivalent thermal capacity can also be 
explained by the use of plasterboard which creates a thin air layer due to the glue points. The values of the equivalent thermal properties found will naturally take into account the impact of the plasterboard.

\subsection{TRNSYS simulations vs in situ tests}

The studied residential building (see Fig. 8) was modelled in the TRNSYS 18 environment. The internal loads and shading scenario were established based on a survey of occupant habits and sensor analysis (shading contact sensors). In particular, the natural and manual early morning ventilation by opening the windows was taken into account to be more realistic (see highlighting in Fig.24). Figs. 24 to 26 compare the TRNSYS results with the in situ measurements during the warmest week. After a calibration procedure, mainly on the shading scenario during the periods of direct sunlight and on the solar absorption coefficient of the external faces, we found a satisfactory correlation. Finally, we found a root mean square error of $0.77 \mathrm{~K}$ on the air temperature between the TRNSYS outputs and the in situ measurements, which is equivalent to the sensor uncertainty $(0.5 \mathrm{~K}) .89 \%$ of the TRNSYS air temperature outputs are contained within the uncertainty range (in black on Fig. 24) of the sensors in addition to a satisfactory shape of the curves in terms of dynamics. We consider that these results validate our equivalent thermal properties.

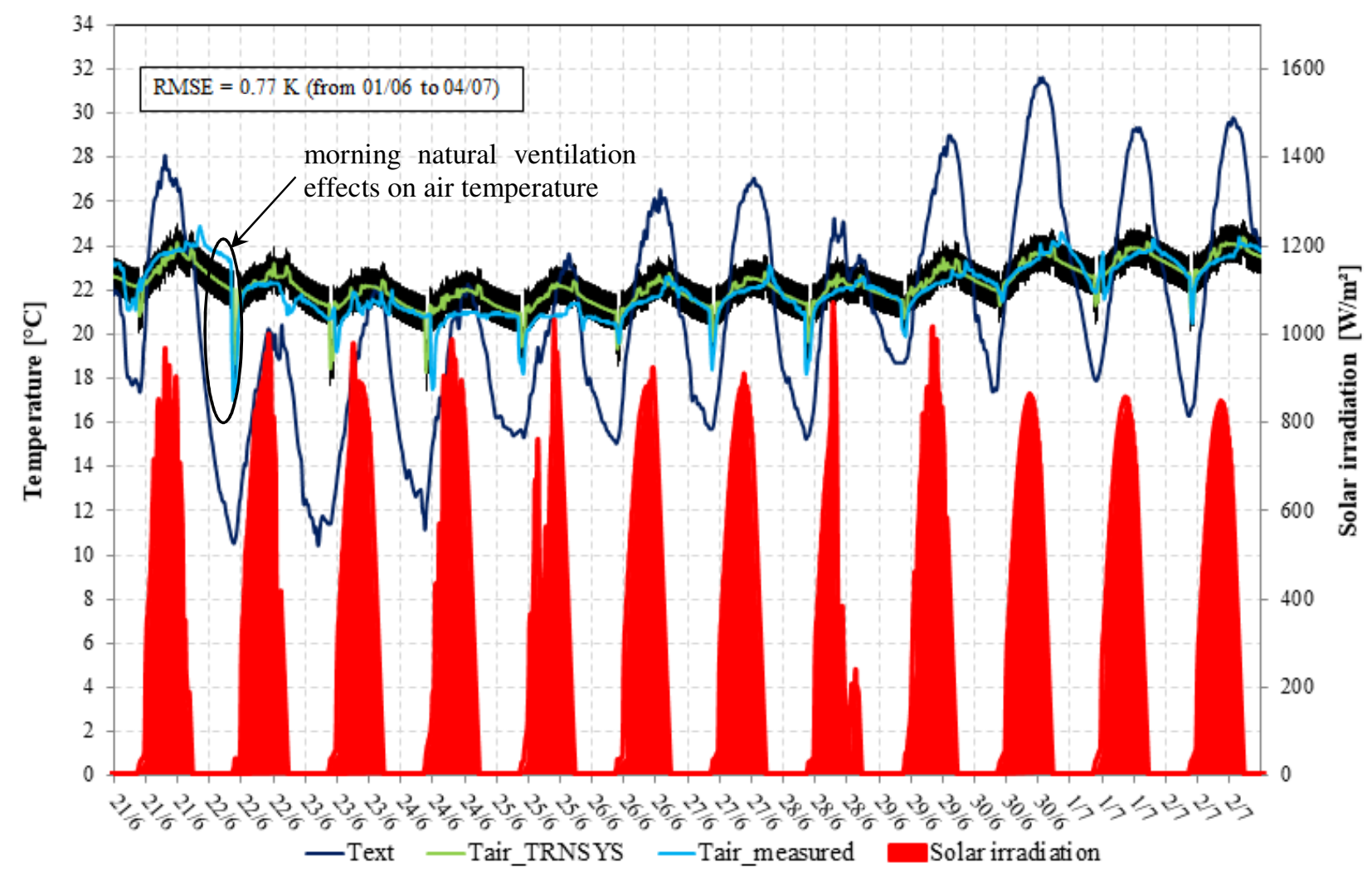

Figure 24: Air temperatures comparison between TRNSYS outputs and in situ test during the hottest week (uncertainty range in black).

In particular, we observe the strong and punctual impact of natural morning ventilation in this room. We also observe an efficient thermal behaviour of the building in terms of summer thermal comfort with high temperature damping and low indoor temperatures compared to outdoor temperatures. These data show that integrated insulation clay hollow blocks building can naturally provide comfortable conditions in summer, although the thermal mass is lower than that of a concrete building for example. Figure 25 shows the hottest day of the test period. The uncertainty range has been plotted to prove the good correlation, at least for this day. 


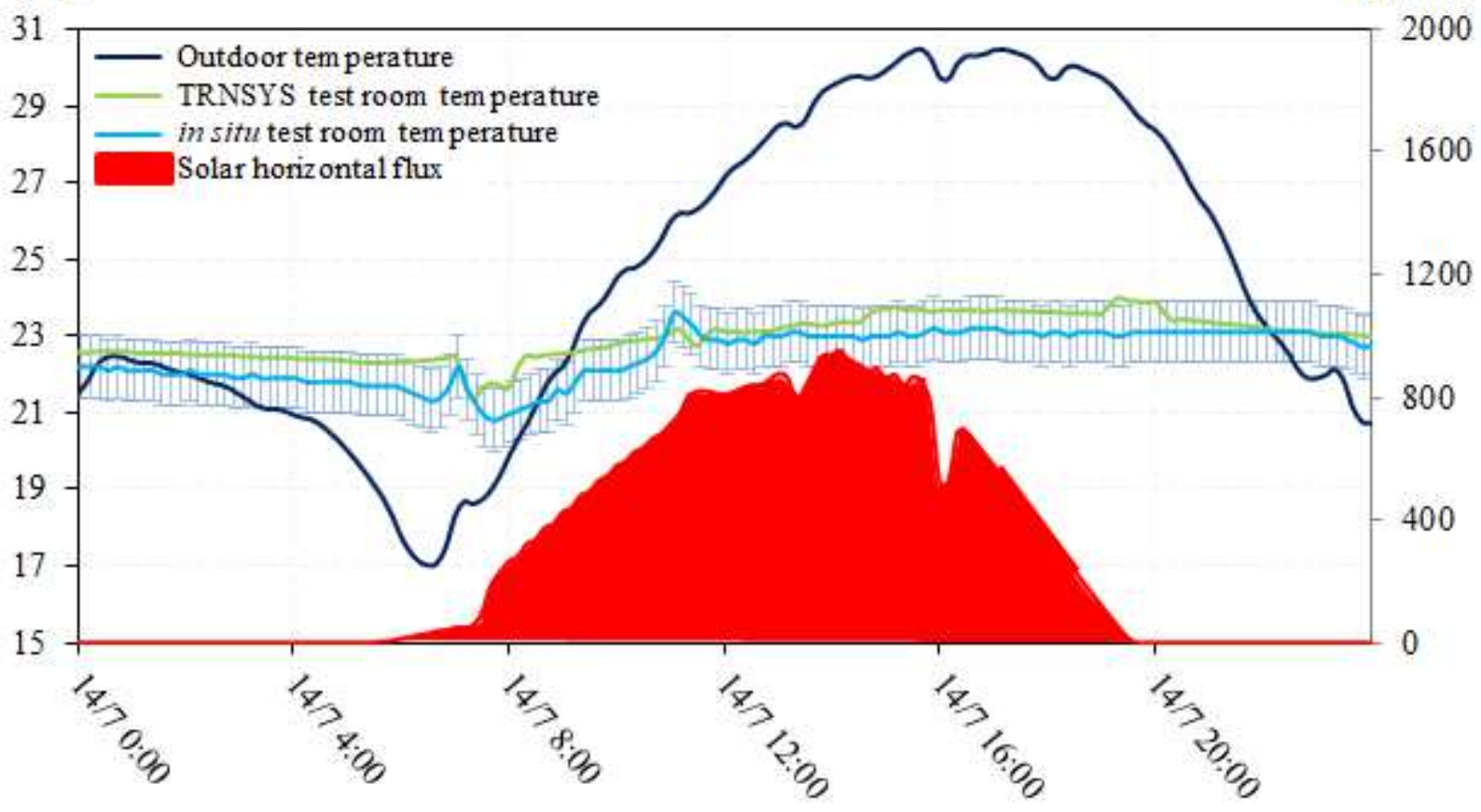

Figure 25: Air temperatures comparison between TRNSYS outputs and in situ test during the hottest day.

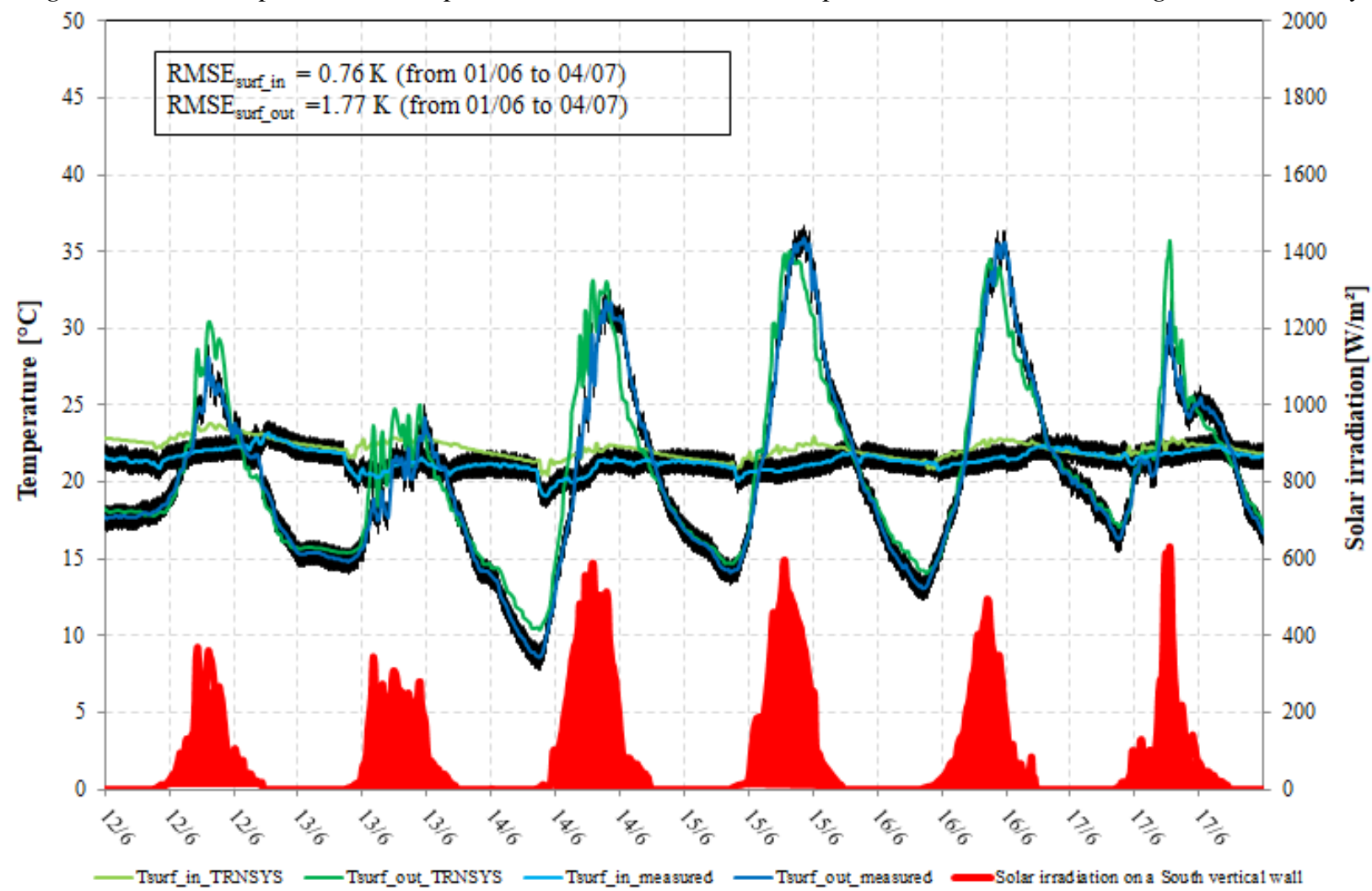

Figure 26: Inside and outside South wall temperatures comparison between TRNSYS outputs and in situ test during the hottest week (uncertainty range in black)

We also compared the indoor and outdoor wall temperatures between the TRNSYS outputs and the in situ measurements. We also found a rather low RMSE, mainly for the inner south wall temperature, with a value close to the sensor uncertainty $(0.76 \mathrm{~K})$. For the external south wall temperature, the calibration of the solar absorptivity coefficient was performed and this is the best fit we can get. Here more parameters influence the output (wind effect, surface conditions, emissivity, humidity), but the RMSE remains low. Finally, we observe a satisfactory correlation between TRNSYS outputs for wall temperatures and in situ measurements, especially for the interior face, which allows us to validate the identification procedure. 


\section{Discussion}

Finally, thanks to statistical indicators (RMSE) and observations, we consider the previously determined equivalent thermal properties as valid based on the satisfactory correlations between in situ measurements and TRNSYS simulations using equivalent thermal properties to simulate a complex integrated insulation clay hollow block. Furthermore, it is interesting to note that our validation procedure is based on a discretized finite difference model whereas TRNSYS uses a conduction transfer function CTF to calculate the 1D transient heat conduction through multi-layer envelope components, which is a different and complementary method [28]. Finally, these in situ tests validate the relatively low values of equivalent thermal capacities found for hollow clay bricks, which is confirmed by the application of the whole protocol to other blocks that also led to low thermal capacities, except for solid aerated concrete. Furthermore, Faye et al [15] also found experimentally (using realistic periodic thermal loads) very low values of equivalent thermal capacity for $30 \mathrm{~cm}$ thick hollow clay blocks (without integrated insulation): $157 \mathrm{~kJ} \cdot \mathrm{m}^{-3} \cdot \mathrm{K}^{-1}$ while we found here for a $36 \mathrm{~cm}$ thick hollow clay block with integrated insulation an equivalent thermal capacity value of $269.5 \mathrm{~kJ} \cdot \mathrm{m}^{-3} \cdot \mathrm{K}^{-1}$.

\section{Conclusion}

A complete numerical and experimental procedure has been implemented to evaluate the equivalent thermal properties of complex wall building blocks (integrated insulation clay hollow blocks). This procedure is based on laboratory tests on a real wall sample of $1 \mathrm{~m}^{2}, 1 \mathrm{D}$ and 2D finite differences numerical models, TRNSYS simulations and in situ tests. The results show a successful calibration of the 1D model based on experimental data. Finally, the equivalent thermal properties of the material were found for a $36 \mathrm{~cm}$ thick block (CLIMAmur 36). It was interesting to show that these values (on heat capacity in $\mathrm{J}_{\mathrm{m}} \mathrm{m}^{-3} \cdot \mathrm{K}^{-1}$ ) were lower than the average values of the properties of the two materials as a function of their proportion. This point shows the complexity of evaluating these equivalent values. An experimental study also shows the of the inner face coating choice (plasterboard or plaster coating) on the dynamic behaviour of the wall. The impact of the air layer created by the glued plasterboards is important and must be taken into account in the wall modelling in order to correctly represent the dynamic behaviour of the wall. The equivalent thermal properties proposed here take into account the impact of this plasterboard. In the future, other block references should be tested to obtain their equivalent properties. Some other references (CLIMAmur 30, GF R20, R37) have already been tested but not to the extent of in situ tests which are obviously difficult and heavy to implement (see Table 6). Only 1D models and experimental tests on $1 \mathrm{~m}^{2}$ wall samples have been performed. However, these tests confirm the trend of relatively low equivalent thermal capacities. An experimental test on solid cellular concrete blocks was also carried out to compare its properties with hollow clay blocks. Finally, we provide in table 6 the thermal properties to be implemented in building dynamic energy simulation tools:

Table 6: Equivalent thermal properties for several blocks.

\begin{tabular}{ccccccc} 
& CLIMAmur 36 & CLIMAmur 30 & R 37 & GF R20 & Aerated concrete & \\
\hline$\rho_{e q}$ & 630 & 630 & 690 & 700 & 450 & $\mathrm{~kg} \cdot \mathrm{m}^{-3}$ \\
$c_{p e q}$ & 430 & 430 & 435 & 475 & 800 & $\mathrm{~J} \cdot \mathrm{kg}^{-1} \cdot \mathrm{K}^{-1}$ \\
$\lambda_{e q}$ & 0.08 & 0.08 & 0.12 & 0.20 & 0.11 & $\mathrm{~W} \cdot \mathrm{m}^{-1} \cdot \mathrm{K}^{-1}$
\end{tabular}

Other studies would also be relevant. Indeed, some authors have shown the great sensitivity of the thermal dynamics of this type of block (clay) to moisture transfers $[29,30]$ which could modify the equivalent thermal properties. The guarded hot box would allow a new campaign to be carried out by adding these water transfers. 


\section{Acknowledgement}

We thank the Wienerberger Company for their technical and logistical support and the Arconic Company and Professor Monica Siroux for their financial support.

\section{Declaration of interest statement}

We declare there is no potential conflict of interest to report and that all this study has been conducted independently.

\section{Nomenclature}

$B \mathrm{i}, \quad$ numerical Biot number, -

$c_{p}, \quad$ heat capacity, $J \cdot \mathrm{kg}^{-1} \cdot \mathrm{K}^{-1}$

$e$, brick thickness, $m$

Fo, numerical Fourier number,-

$h$, superficial exchange coefficient, $W \cdot m^{-2} \cdot K^{-1}$

m, mass, $\mathrm{kg}$

$R \quad$ thermal resistance, $m^{2} \cdot K \cdot W^{1}$

$T$ temperature, ${ }^{\circ} \mathrm{C}$

$t$ time, $s$ or $h$

$V, \quad$ volume, $m^{3}$

$\Delta T, \quad$ temperature difference, $K$

$\delta$, penetration depth, $m$

$\lambda$, thermal conductivity, $W \cdot m^{-1} \cdot K^{-1}$

$\rho \quad$ density, $k g . m^{-3}$

$\varphi, \quad$ heat flux density, $W \cdot m^{-2}$

$\bar{\varphi}, \quad$ mean heat flux density, $W \cdot m^{-2}$

$\tau, \quad$ cycle period, $s$

\section{Subscripts and exponents}

board, plasterboard

block, block

clay, clay

coating, plaster coating

$e, \quad$ exterior

exp, experimental

$i, \quad$ interior

eq, equivalent

num, numerical

$\mathrm{rad}, \quad$ radiative

surf, surface

tot, total

w, wall 
wool, mineral wool

\section{References}

[1] French Thermal Regulation "Réglementation thermique 2012", http://www.rt-batiment.fr/ (accessed 23.05.20).

[2] The Intergovernmental Panel on Climate Change, https://www.ipcc.ch/ (accessed 23.05.20).

[3] Jiapeng Sun, Liang Fang, Numerical simulation of concrete hollow bricks by the finite volume method, International Journal of Heat and Mass Transfer, Volume 52, Issues 23-24, 2009, Pages 5598-5607, ISSN 0017-9310,

https://doi.org/10.1016/j.ijheatmasstransfer.2009.06.008.

[4] Majed M. Al-Hazmy, Analysis of coupled natural convection-conduction effects on the heat transport through hollow building blocks, Energy and Buildings, Volume 38, Issue 5, 2006, Pages 515-521, ISSN 0378-7788, https://doi.org/10.1016/j.enbuild.2005.08.010.

[5] Mohammed Boukendil, Abdelhalim Abdelbaki, Zaki Zrikem, Numerical simulation of coupled heat transfer through double hollow brick walls: Effects of mortar joint thickness and emissivity, Applied Thermal Engineering, Volume 125, 2017, Pages 1228-1238, ISSN 1359-4311,

https://doi.org/10.1016/j.applthermaleng.2017.07.094.

[6] A. A. Alghamdi, H. A. Alharthi, Multiscale 3D finite-element modelling of the thermal conductivity of clay brick walls, Construction and Building Materials, Volume 157, 2017, Pages 1-9, ISSN 0950-0618, https://doi.org/10.1016/j.conbuildmat.2017.09.081

[7] Y. Gao, J.J. Roux, C. Teodosiu, L.H. Zhao, Reduced linear state model of hollow blocks walls, validation using hot box measurements, Energy and Buildings, Volume 36, Issue 11, 2004, Pages 1107-1115, ISSN 0378-7788, https://doi.org/10.1016/j.enbuild.2004.03.008.

[8] Jan Kočí, Jiří Maděra, Miloš Jerman, Robert Černý, Computational assessment of thermal performance of contemporary ceramic blocks with complex internal geometry in building envelopes, Energy and

Buildings, Volume 99, 2015, Pages 61-66, ISSN 0378-7788

https://doi.org/10.1016/j.enbuild.2015.04.017.

[9] Jan Kočí, Jiří Maděra, Robert Černý, A fast computational approach for the determination of thermal properties of hollow bricks in energy-related calculations, Energy, Volume 83, 2015, Pages 749-755, ISSN 0360-5442,

https://doi.org/10.1016/j.energy.2015.02.084.

[10] Paolo Principi, Roberto Fioretti, Thermal analysis of the application of pcm and low emissivity coating in hollow bricks, Energy and Buildings, Volume 51, 2012, Pages 131-142, ISSN 03787788 ,

https://doi.org/10.1016/j.enbuild.2012.04.022.

[11] Yuan Zhang, Kai Du, Jiapeng He, Liu Yang, Yanjun Li, Shuhong Li, Impact factors analysis on the thermal performance of hollow block wall, Energy and Buildings, Volume 75, 2014, Pages 330-341, ISSN 0378-7788, 
[12] D. L. Tang, L. P. Li, C. F. Song, W. Q. Tao \& Y. L. He (2015) Numerical Thermal Analysis of Applying Insulation Material to Holes in Hollow Brick Walls by the Finite-Volume Method, Numerical Heat Transfer, Part A: Applications, 68:5, 526-54

DOI: $10.1080 / 10407782.2014 .986396$

[13] Ahmad M. Mahmoud, Abdullatif Ben-Nakhi, Ammar Ben-Nakhi \& Rashed Alajmi (2012) Conjugate conduction convection and radiation heat transfer through hollow autoclaved aerated concrete blocks, Journal of Building Performance Simulation, 5:4, 248-262

DOI: $10.1080 / 19401493.2011 .565886$

[14] K. Arendt, M. Krzaczek, J. Florczuk, Numerical analysis by FEM and analytical study of the dynamic thermal behavior of hollow bricks with different cavity concentration, International Journal of Thermal Sciences, Volume 50, Issue 8, 2011, Pages 1543-1553, ISSN 1290-0729,

https://doi.org/10.1016/j.ijthermalsci.2011.02.027.

[15] Mactar Faye, Berangere Lartigue, Vincent Sambou, A new procedure for the experimental measurement of the effective heat capacity of wall elements, Energy and Buildings, Volume 103, 2015, Pages 62-69, ISSN 0378-7788,

https://doi.org/10.1016/j.enbuild.2015.05.054.

[16] Emanuele Habib, Marta Cianfrini, Roberto de Lieto Vollaro, Definition of Parameters Useful to describe dynamic Thermal Behavior of Hollow Bricks, Energy Procedia, Volume 126, 2017, Pages 50-57, ISSN 1876-6102, https://doi.org/10.1016/j.egypro.2017.08.056.

[17] J.M. Sala, A. Urresti, K. Martín, I. Flores, A. Apaolaza, Static and dynamic thermal characterisation of a hollow brick wall: Tests and numerical analysis, Energy and Buildings, Volume 40, Issue 8, 2008, Pages 1513-1520, ISSN 0378-7788, https://doi.org/10.1016/j.enbuild.2008.02.011.

[18] Zukowski, G. Haese, Experimental and numerical investigation of a hollow brick filled with perlite insulation, Energy and Buildings, Volume 42, Issue 9, 2010, Pages 1402-1408, ISSN 03787788 ,

https://doi.org/10.1016/j.enbuild.2010.03.009

[19] CTTB (1997), Caractéristiques et performances thermiques du mur tout terre cuite, étude de la paroi seule, mesures expérimentales, 6 pages

[20] Yanna Gao, Fan He, Xi Meng, Ziyun Wang, Ming Zhang, Hanting Yu, Weijun Gao, Thermal behavior analysis of hollow bricks filled with phase-change material (PCM), Journal of Building Engineering, Volume 31, 2020, 101447, ISSN 2352-7102,

https://doi.org/10.1016/j.jobe.2020.101447. 
[21] Jing Li, Xi Meng, Yanna Gao, Wei Mao, Tao Luo, Lili Zhang, Effect of the insulation materials filling on the thermal performance of sintered hollow bricks, Case Studies in Thermal Engineering,

Volume 11, 2018, Pages 62-70, ISSN 2214-157X, https://doi.org/10.1016/j.csite.2017.12.007.

[22] Chaoping Hou, Xi Meng, Yanna Gao, Wei Mao, Enshen Long, Effect of the insulation materials filling on the thermal performance of sintered hollow bricks under the air-conditioning intermittent operation, Case Studies in Construction Materials, Volume 8, 2018, Pages 217-225, ISSN 2214-5095,

https://doi.org/10.1016/j.cscm.2018.02.007.

[23] Julien Quinten, Véronique Feldheim, Mixed equivalent wall method for dynamic modelling of thermal bridges: Application to 2-D details of building envelope, Energy and Buildings, Volume 183, 2019, Pages 697-712, ISSN 0378-7788,

https://doi.org/10.1016/j.enbuild.2018.11.004

[24] Jan Kośny, Elizabeth Kossecka, Multi-dimensional heat transfer through complex building envelope assemblies in hourly energy simulation programs, Energy and Buildings, Volume 34, Issue 5, 2002,

Pages 445-454, ISSN 0378-7788,

https://doi.org/10.1016/S0378-7788(01)00122-0

[25] Arianna Brambilla, Thomas Jusselme, Preventing overheating in offices through thermal inertial properties of compressed earth bricks: A study on a real scale prototype, Energy and Buildings, Volume 156, 2017, Pages 281-292, ISSN 0378-7788,

https://doi.org/10.1016/j.enbuild.2017.09.070

[26] Eduardo Roque, Romeu Vicente, Ricardo M.S.F. Almeida, J. Mendes da Silva, Ana Vaz Ferreira, Thermal characterisation of traditional wall solution of built heritage using the simple hot box-heat flow meter method: In situ measurements and numerical simulation, Applied Thermal Engineering, Volume 169, 2020, 114935, ISSN 1359-4311,

https://doi.org/10.1016/j.applthermaleng.2020.114935.

[27] D. Sukamto, F. Gloriant and M. Siroux, Improved value of temperature different on climatic chamber for thermal conditions, IOP Conference Series: Materials Science and Engineering, Volume 673, Broad Exposure to Science and Technology 2019 (BEST2019) 7-8 August 2019, Bali, Indonesia

[28] B. Delcroix et al. (2012), Conduction transfer functions in TRNSYS multizone building model: current implementation, limitations and possible improvements, Fifth National Conference of IBPSA-USA, Madison, Wisconsin.

[29] Gerson Henrique dos Santos, Nathan Mendes, Heat, air and moisture transfer through hollow porous blocks, International Journal of Heat and Mass Transfer, Volume 52, Issues 9-10, 2009, Pages 2390-2398, ISSN 0017-9310, https://doi.org/10.1016/j.ijheatmasstransfer.2008.11.003

[30] Simon Schmidt, Manuel Lindauer et Michaela Hoppe (2012), Comparing TRNSYS and WUFI®plus simulation models- illustrated on models validated on measurements, Proceedings of the 5th IBPC, Kyoto, Japan 